Elsevier Editorial System(tm) for Earth and Planetary Science Letters

Manuscript Draft

Manuscript Number: EPSL-D-05-00905R2

Title: Analyses of shocked quartz at the global K-P boundary indicate an origin from a single, high-angle, oblique impact at Chicxulub

Article Type: Regular Article

Section/Category:

Keywords: Keywords: shocked quartz, K-P boundary, Chicxulub, obliquity of impact, impact cratering, Leg LL44 site GPC3, Ocean Drilling Program, JOIDES Resolution, Leg 198 site 1209, Leg 130 site 803D, Leg 208 site 1262, Leg 207 site 1258A.

Corresponding Author: Dr Cristiano Lana, PhD

Corresponding Author's Institution: Stellenbosch University

First Author: Joanna Morgan, $\mathrm{PhD}$

Order of Authors: Joanna Morgan, PhD; Cristiano Lana, PhD; Anton Kearsley; Barry Coles; Claire Belcher, PhD; Sandro Montanari, PhD; Enrique Dias-Martinez; Antonio Barbosa, MSc; Virginio Neumann, PhD

Manuscript Region of Origin:

Abstract: The precise cause and timing of the Cretaceous-Paleocene (K-P) mass extinction 65 million years ago remains a matter of debate. Many advocate that the extinction was caused by a meteorite impact at Chicxulub, Mexico, and a number of potential kill-mechanisms have been proposed for this. Although we now have good constraints on the size of this impact and chemistry of the target rocks, estimates of its environmental consequences are hindered by a lack of knowledge about the obliquity of this impact. An oblique impact is likely to have been far more catastrophic than a sub-vertical one, because greater volumes of volatiles would have been released into the atmosphere. The principal purpose of this study was to 
characterize shocked quartz within distal K-P ejecta, to investigate whether the quartz distribution carried a signature of the direction and angle of impact. Our analyses show that the total number, maximum and average size of shocked quartz grains all decrease gradually with paleodistance from Chicxulub. We do not find particularly high abundances in Pacific sites relative to Atlantic and European sites, as has been previously reported, and the size-distribution around Chicxulub is relatively symmetric. Ejecta samples at any one site display features that are indicative of a wide range of shock pressures, but the mean degree of shock increases with paleodistance. These shock- and size-distributions are both consistent with the K-P layer having been formed by a single impact at Chicxulub. One site in the South Atlantic contains quartz indicating an anomalously high average shock degree, that may be indicative of an oblique impact with an uprange direction to the southeast $\pm 45^{\circ}$. The apparent continuous coverage of proximal ejecta in this quadrant of the crater, however, suggests a relatively high impact angle of $>45^{\circ}$. We conclude that some of the more extreme predictions of the environmental consequences of a low-angle impact at Chicxulub are probably not applicable. 


\title{
Analyses of shocked quartz at the global K-P boundary indicate an origin from a single, high-angle, oblique impact at Chicxulub
}

\author{
Joanna Morgan ${ }^{1}$, Cristiano Lana ${ }^{1}$, Anton Kearsley ${ }^{2}$, Barry Coles $^{1}$, Claire Belcher ${ }^{3}$, Sandro \\ Montanari $^{4}$, Enrique Díaz-Martínez ${ }^{5}$, Antonio Barbosa ${ }^{6}$, Virginio Neumann ${ }^{6}$ \\ ${ }^{1}$ Earth Science and Engineering, Imperial College London, South Kensington Campus, SW7 2 AZ, \\ London, UK \\ ${ }^{2}$ Department of Mineralogy, The Nature History Museum, Cromwell Road, SW7 5BD, London, UK \\ ${ }^{3}$ Department of Geology, Royal Holloway University of London, Egham TW20 0EX, UK \\ ${ }^{4}$ Osservatorio Geologico di Coldigioco 62020 Frontale di Apiro, Italy \\ ${ }^{5}$ Geological Survey of Spain (IGME), Calera 1, Tres Cantos 28760, Madrid, Spain \\ ${ }^{6}$ Departamento de Geologia, Universidade Federal de Pernambuco, 50.740-530, Recife (PE), \\ Brasil
}

*Email: j.morgan@imperial.ac.uk: Fax: $\underline{00442075947444}$

\begin{abstract}
The precise cause and timing of the Cretaceous-Paleocene (K-P) mass extinction 65 million years ago remains a matter of debate. Many advocate that the extinction was caused by a meteorite impact at Chicxulub, Mexico, and a number of potential kill-mechanisms have been proposed for this. Although we now have good constraints on the size of this impact and chemistry of the target rocks, estimates of its environmental consequences are hindered by a lack of knowledge about the obliquity of this impact. An oblique impact is likely to have been far more catastrophic than a subvertical one, because greater volumes of volatiles would have been released into the atmosphere. The principal purpose of this study was to characterize shocked quart with in distal K-P ejecta, to investigate whether the quartz distribution carried a signature of the direction and angle of impact. Our analyses show that the total number, maximum and average size of shocked quartz grains all decrease gradually with paleodistance from Chicxulub. We do not find particularly high abundances in Pacific sites relative to Atlantic and European sites, as has been previously reported, and the size-distribution around Chicxulub is relatively symmetric. Ejecta samples at any one site
\end{abstract}


display features that are indicative of a wide range of shock pressures, but the mean degree of shock increases with paleodistance. These shock- and size-distributions are both consistent with the K-P layer having been formed by a single impact at Chicxulub. One site in the South Atlantic contains quartz indicating an anomalously high average shock degree, that may be indicative of an oblique impact with an uprange direction to the southeast $\pm 45^{\circ}$. The apparent continuous coverage of proximal ejecta in this quadrant of the crater, however, suggests a relatively high impact angle of $>$ $45^{\circ}$. We conclude that some of the more extreme predictions of the environmental consequences of a low-angle impact at Chicxulub are probably not applicable.

Keywords: shocked quartz, K-P boundary, Chicxulub, obliquity of impact, impact cratering, Leg LL44 site GPC3, Ocean Drilling Program, JOIDES Resolution, Leg 198 site 1209, Leg 130 site 803D, Leg 208 site 1262, Leg 207 site 1258A.

\section{Introduction}

Alvarez et al. [1] identified an extraterrestrial signature with in the K-P boundary clay layer and, following a lengthy debate, this layer is now universally agreed to have been formed by a meteorite impact. The K-P layer also contains highly shocked terrestrial minerals (quartz, feldspar and zircon) that originated from rocks at the impact site, as well as impact-derived Ni-rich spinel [28]. After the Chicxulub impact crater was discovered [9] numerous studies of this crater and the KP boundary led to widespread agreement that Chicxulub was the site of a K-P boundary impact, with a few notable exceptions [10-11]. The cause of the K-P mass extinction is still contentious, and the precise role of the Chicxulub impact and Deccan volcanism remains a matter of some debate [e.g. 12-13]. The impact would have released dust and climatically active gasses into the atmosphere, and caused a period of extreme temperature change and darkness, but calculations of the nature, extent and duration of these changes differ [e.g. 14-17]. Estimates of climatic effects are dependent, in part, upon knowledge of the energy of impact, the chemistry of the target rocks, and the obliquity of impact. An oblique impact would have been much more damaging than a sub- 
vertical one because the shock wave would be more focused with in the near-surface, volatile-rich, sedimentary rocks, and this would cause the release of higher volumes of climatically active carbon- and sulfur-rich gasses. [17-19]. The impact size and target chemistry are now reasonably well constrained [e.g. 9, 20], but the obliquity of impact is unknown.

The best indicator of direction of impact for craters on other planetary bodies is found in the asymmetric distribution of their proximal ejecta (Fig. 1a). Highly oblique impacts $(<10$ degrees) produce elliptical craters and a butterfly ejecta pattern with ejecta-free zones in the up and downrange directions. For impact angles of greater than $\sim 15$ degrees near-circular craters are produced and, for oblique impact angles up to $\sim 45$ degrees, ejecta is missing in the uprange direction [21]. Chicxulub is roughly circular $[9,20]$, suggesting an impact angle of $>15$ degrees. Although asymmetries in the apparent crater structure have been used to estimate impact angle and direction $[18,22]$, the feature applied (offset of the central uplift) have been shown not to be diagnostic of impact direction for craters on Venus [23]. At Chicxulub much of the proximal ejecta is buried and, as the impact site was submerged continental shelf, is likely to have been redistributed by tsunamis or erosion immediately or soon after impact.

During the excavation stage of cratering the so-called ejecta curtain material is ejected at particle velocities of up to $\sim 2 \mathrm{kms}^{-1}$ to form the proximal ejecta deposits [24-25], and for Chicxulub these deposits should extend up to $\sim 400 \mathrm{~km}$ from the impact site. This ejection mechanism cannot explain the presence of shocked quartz in the global K-P layer as velocities of $>9 \mathrm{kms}^{-1}$ are required to eject quartz to the other side of the planet. The only plausible explanation is that these ejecta were accelerated to high speeds within the expanding vapor plume [25]. The expanding plume would consist of a mixture of vapor, melt and clastic minerals metamorphosed at different shock pressures. However, the precise kinematics of ejection are unknown and different assumptions about the velocity/mass distribution lead to quite different final distributions of ejecta [26-27].

Observational, experimental and numerical modeling of oblique impacts all indicate that vapor plumes initially expand in the downrange direction $[19,28,29]$. Hence it appears plausible 
that the shocked quartz could be ejected in an asymmetric pattern from the impact site. Previous studies of the K-P ejecta have suggested some intriguing asymmetries in the distal ejecta pattern $[18,30,31]$, with shocked quartz being more abundant in sites to the west of Chicxulub [30, 31] However, these observations are based upon data acquired by a number of groups, who have adopted different sampling and/or analytical procedures. Detailed mineralogical studies that report the absolute abundance and grain size of shocked quartz are rare [31, 32, 33], and some sites are better documented than others. Hence, it is difficult to make a quantitative assessment of asymmetries in the distribution of the distal ejecta using the existing data alone.

This paper reports the results of a new systematic study of shocked quartz from the global K-P boundary that covered a range of paleodistances and azimuths (Fig. 1b; Table 1). Observations of the grain size and degree of shock in quartz have been made using optical and scanning electron microscopy (SEM). The objective of this study was to evaluate whether the shocked quartz is asymmetrically distributed around the crater and, if so, whether that distribution offers a clue to the direction and angle of impact at Chicxulub. In contrast to previous studies, site-to-site comparisons of these new data can be made with confidence because the same protocol was used to analyze each sample.

\section{Sampling and Analytical Procedures}

To cover a range of paleodistances and azimuths, a number of sites in Europe, Brazil, New Zealand, North America, and the Pacific and Atlantic ocean regions were chosen for this study (Fig. 1b; Table 1). Samples were collected from a number of outcrops at each location, to investigate whether there was significant local variation in the K-P layer. In each case we attempted to sample the entire shocked quartz-bearing layer. For North Americ an sites, the Fireball Layer and Boundary Layer (see definition in [7]) were analyzed separately. In New Zealand we sampled the 1-cm thick K-P layer, and in European sections where K-P layer thickness varies between 2 and $4 \mathrm{~cm}$, we took samples from the 2-cm thick sections. Samples from the Ontong Java Plateau (ODP site 803D), 
Demerara Rise (ODP site 1258A), Shatsky Rise (ODP site 1209), Walvis Ridge (ODP site 1262) and North Pacific (site GPC3) were taken from intervals where either spherules or shocked quartz had been previously identified.

\section{Figure 1}

Optical analyses were used to determine the abundance and size of shocked quartz in the bulk volume of K-P rocks in samples from all land-based locations. Quartz grains were extracted after sequential leaching of fossil, carbonate and clay mineral components (as described in Bostwick and Kyte [31]) and dry sieving of the remaining mineral separate. Analys es were carried out on grains extracted from $50 \mathrm{~g}$ bulk samples and then mounted in to smear slides with ultra violet cement, following the methodology of Montanari and Ko eberl [33]. Shocked quartz grains were identified and marked on the slides, and then counted and measured. The approximate total number of quartz (shocked and unshocked) was estimated using a subset of the prepared slides.

The identification of a K-P section in the Poty Quarry in Northeastern Brazil has been the subject of some debate ([34-37]). We have analyzed ten $50 \mathrm{~g}$ samples from the Poty section from locations where shocked quartz had been reported. Five samples were extracted from the base of a 20 to $50 \mathrm{~cm}$ thick layer of limestone breccia, where Koutsoukos [35] suggested that $\sim 20 \%$ of the 300 quartz grains counted were shocked. The remaining samples were from the overlying layers from which Koutsoukos [35] also reported grains of shocked quartz.

SEM was used to determine the size-distribution of the smaller grains of shocked quart from all land and marine sites, as well as to document the shock features. The mineral separates for SEM analys is were extracted from one gram of sample and attached to 1-cm diameter carbon tapes mounted on aluminum stubs. Backscattered electron imagery (BEI) and X-ray microanalysis (EDS) of shocked minerals were carried out on a JEOL JSM840 SEM with an Oxford Instruments exL Pentafet energy X-ray spectrometer (EDS) at the Natural History Museum, London. All shocked mineral grains were photographed, counted and measured, comprising a dataset of nearly 5500 shocked grains in total. 


\section{Results}

\subsection{Optical analyses}

In Table 2 we show the number of shocked quartz grains observed as well as an estimate of the total number of quartz grains, and the maximum and average size for each sample. During the course of the optical analysis we noted that the shallow marine sites from Europe and New Zealand contained large amounts of unshocked quartz with grain sizes $>60 \mu \mathrm{m}$. The high number of unshocked quartz grains in these samples is indicative of their depositional environment in shallow marine seas (Table 1) (e.g.[38]). We sieved a number of samples from these sites to recover grains of $<100 \mu \mathrm{m}$ in size, to investigate whether the smaller grains of shocked quart were also diluted by unshocked grains (bottom half of Table 2). The dilution is similar in both size ranges.

Shocked quartz is abundant in the North American fireball layer with a few thousand shocked quartz grains per $50 \mathrm{~g}$ sample. The maximum observed grain size in the Fireball Layer is $500 \mu \mathrm{m}$, but the majority of shocked grains were in the size range from 100 to $200 \mu \mathrm{m}$ (Table 2). The Boundary Claystone yielded relatively few shocked grains. As has been documented in previous optical studies (e.g., [7]), there is no substantial lateral variation in grain size from the southernmost to the northernmost K-P sites in North America. European sites have between a few and 20 shocked quartz grains per 50 g sample, and shocked quartz is relatively rare in New Zealand. The mineral separate samples of the size range $<100 \mu \mathrm{m}$ consistently contain more shocked quartz grains than the separates with a size range of $>60 \mu \mathrm{m}$ (Table 2). On average there are $\sim 1.8$ times more shocked quartz grains in the smaller size-range. The abundance of shocked quartz does not vary substantially between samples from the same location, with individual counts varying by less than a factor of 2. Our results are consistent with those of previous optical analyses (e.g. [7] ).

Our mineral separates $(\sim 0.1$ gram) from the limestone breccia at Poty Quarry comprise quartz $(50-60 \%)$, feldspar $(40-50 \%)$ and trace minerals $(<1 \%)$ such as pyroxene, zircon and sphene. Some quartz and feldspar were inten sely fractured, but we did not find a single quartz grain with planar deformation features (PDF). Some quartz grains showed more than two parallel 
fracture planes, but they were widely spaced and discontinuous. It appears that Poty Quarry is not a K-P section.

\subsection{SEM analyses}

Results from our SEM analysis of $1 \mathrm{~g}$ samples (Table 3) show that much larger numbers of shocked quartz are identified using the SEM than with the optical studies. For example, there is an average of 55 shocked grains within a $1 \mathrm{~g}$ SEM sample from the bottom centimeter at three sites in Italy, whereas, in the optical analysis, the average is 10.4 grains per $50 \mathrm{~g}$ in the size range $>60 \mu \mathrm{m}$ and 19 grains per $g$ for particle sizes $<100 \mu \mathrm{m}$ (Table 2). A his to gram of the size of shocked quartz grains, along with the mean at each site (Fig. 2) shows that more than $70 \%$ of the shocked grains are in the size range from 20 to $80 \mu \mathrm{m}$.

Shocked quartz is most abundant in samples from the southernmost sites in North America (Clear Creek North, Berwind Canyon and Madrid East South) with about 800 shocked quartz grains per $0.5 \mathrm{~g}$ (Table 3). The K-P sites in Canada appear to contain slightly less shocked quartz (640 to 760 shocked quartz grains per $0.5 \mathrm{~g}$ of sample). At the next closest site, ODP site $1258 \mathrm{~A}$ in the South Atlantic, the number of shocked quartz grains varies between 42 and 68 per g sample from the $3 \mathrm{~cm}$-thick K-P boundary interval.

\section{Figure 2}

The largest numbers of shocked quartz grains in Europe were found at the base of the clay layer in the bottom centimeter, whereas in samples from the Pacific site GPC3 the number of shocked quartz grains varies unsystematically with depth (Table 3). Samples from the ODP site 1258A, in the Atlantic, contain between 11 and 18 shocked quartz grains per g. ODP sites 803 and 1209 in the Pacific, and the site in New Zealand, contain between 2 and 11 shocked quartz grains per g of sample.

\subsection{Dilution and Reproducibility}

We were concerned that the large numbers of unshocked quartz at some sites may have affected our counting, as their presence could make it more difficult to identify the shocked quartz. 
One sample from the bottom centimeter at Petriccio contained unusually low volumes of un shocked quartz (50-100 grains), while the other sample contained 500-1000 grains (Table 3). The number of shocked quartz grains identified in these two samples was 74 and 52 respectively. This suggests that dilution by large numbers of unshocked quartz could reduce the number of shocked quartz identified by $\sim 40 \%$.

The reproducibility of the methods used was tested using aliquots of the same sample. Four aliquots of a sample from Caravaca (Cara-1-2-03-2006a, -2006b, -2006c and -2006d) were separated for optical and SEM observation (Table 4a). The results from optical analysis varied from 4 to 8 grains per $50 \mathrm{~g}$ of sample, giving a mean of 5.5 grains and standard deviation of 2.3 grains (Table 4a). For SEM analysis a mean of 30 grains (standard deviation of 10 grains) was obtained (Table 4a). In each case, the original counts of 5 and 35 grains at Caravaca 1 (Tables 2 and 3) are within 1 standard deviation of the means derived from the aliquots.

The variation in counts from the same sample is similar to the variation between samples from the same location, with most individual counts varying by less than a factor of 2 .

\subsection{Shock features}

Our optical and SEM analyses show that shocked quartz (Fig. 3a), are found in all sites sampled except for Poty Quarry (Tables 2-3), in accordance with previous reports on K-P sites from North America [5-7], the Pacific plate [31, 32] and Europe [8]. We have identified quartz characterized by planar fractures, PDF and shock mosaicism, which have been shown to be indicative of increasing degrees of shock pressure [39]. Most planes of PDF are sharply defined and continuous across the grain (Fig. 3a), but some are only observed around the margins of grains. Some quartz grains with more than one set of PDF are partially isotropic (Fig. 3b). SEM analysis revealed that several shocked quartz grains show evidence of internal recrystallization (Figs. 3c, d). These quartz grains appear to preserve their original shape, but are recrystallized into aggregates of $1-5 \mu \mathrm{m}$ wide anhedral quartz grains. The aggregates are mostly seen on broken surfaces of the 
grains and are porous, similar in many aspects to the granular (strawberry) textures reported for shocked zircon in K-P samples from North America (Figs. 3c, d) (e.g., [40]).

\section{Figure 3}

In all samples we observed quartz with a range of shock features. With the aim of investigating the degree of shock at each site, we have identified all quartz grains with PDF and documented the number of PDF in every grain (Table 3). It is evident that the proportion of grains with 1, 2 or 3 PDF varies between samples.

In contrast to shocked quartz, shocked zircon is very rare in samples from Europe. We recovered six and eight shocked zircon in the size-range $40-80 \mu \mathrm{m}$ in samples from Petriccio and Caravaca, respectively. SEM analysis indicates that the shocked zircon grains are characterized by one or multiple sets of planar features, which occur as intersecting planes with spacings of between 4 and $8 \mu \mathrm{m}$. Three grains displayed strawberry texture, and this texture has previously been interpreted as a product of recrystallization under high- $\mathrm{T}$ conditions after shock-induced amorphization [41-42]. As for zircon from North American sites (e.g., [40, 43]), the granular texture in the porous zircon from the European sites occurs beneath the original planar surface of subhedral grains (Fig. 4c). The largest zircon grains were polished to half their thickness to expose internal structures (Figs. 4 d-f). The zircon grains with multiple sets of planar features have the oscillatory zoning typical of crystallization in a felsic magma (Fig. 4e, f), but many grains have also preserved core structures. The cores and compositional zoning are best identified through cathodoluminescence imaging, but the overall poor (dark) luminescence of these grains makes unraveling of the more subtle internal structures difficult and sometimes impossible (Fig. 4f). This is particularly so for recrystallized zircon, which is characterized by extremely fine-grained crystals.

\section{Figure 4}

\section{Discussion}

\subsection{Apparent paleodistance and a zimuth}


As discussed in the introduction, the only plausible mechanism for distributing shocked quartz around the globe is by their acceleration to high velocity within the expanding vapor plume. If the impact at Chic xulub had been sub-vertical, we would expect a symmetrical ejection pattern in all directions. One factor that affects the final ejecta distribution is the Earth's rotation, as sites to the west of Chicxulub move closer as the ejecta is traveling towards them. To partially remove this effect, we have calculated the flight time of ejecta with a take-off angle of $45^{\circ}$ to each site, and used this to determine the distance and azimuth of each site from Chic xulub when the ejecta arrived. We refer to this as the apparent distance and azimuth at each site (Table 4b). For example, the Canadian sites moved $\sim 300 \mathrm{~km}$ westwards while these ejecta were in flight, and, at the time of arrival, the site was $\sim 100 \mathrm{~km}$ closer to Chicxulub at an azimuth of $341^{\circ}$.

\subsection{Abundance and size-dis tribution of shocked quartz}

It is apparent from Tables 2 and 3 that more shocked quartz grains per g were identified through SEM than optical analyses on all samples for which both methods were used. The grain size plots in Figure 2 show that more than $70 \%$ of the shocked quartz grains are smaller than $80 \mu \mathrm{m}$, thus, a large fraction of the grains are not detectable by optical analysis. The optical and SEM results are only weakly correlated (correlation coefficient $\mathrm{R}=0.55$ ) and reflect the observed variation on a local scale within the K-P layer. The $1 \mathrm{~g}$ aliquots of the same sample showed a factor of 2 variation, with a minimum of 19 and maximum of 38 shocked quartz grains (Table 4a), and similar variations are found between different samples from the same location (Tables 2 and 3). These local differences may be directly related to initial variability within the plume or subsequent depositional processes, for example bioturbation and re-working would produce some vertical and lateral dispersion. Given the observed dispersion, and in order to obtain a robust estimate of the local size-distribution, we have grouped the data and determined the mean and variance for all samples that were collected reasonably close together. The new group values are indicated in the 
first column of Table 4b. For site-to-site comparisons we are forced to use our SEM data, because optical analyses could only be performed at land-based sites.

Sites in North America have the largest number of shocked quartz grains with $>1400$ grains per $\mathrm{g}$ of sample (Table 4b). Sites between 4000 and $8250 \mathrm{~km}$ have a few 10s of grains per $\mathrm{g}$, and sites located at distances of $>9000 \mathrm{~km}$ have a range of between 5 and 17 grains per g. However, the shocked quartz is located in relatively thin layers in North America, Europe and New Zealand $(\leq 2 \mathrm{~cm})$ and over an extended interval in the Pacific sites. To measure the total abundance at each location, we have estimated the number of shocked quartz grains per unit surface area $\left(\right.$ nos $/ \mathrm{cm}^{2}$ in Table $4 b$, see caption for details). Shocked quartz at Pacific sites is more dispersed than elsewhere. Where detailed sampling has been performed across several 10s of centimeters above and below the K-P iridium peak, for example site 576B (Table 2 in Bostwick and Kyte [31]), the shocked quartz is focused within a relatively thin interval of $>3$ and $<7 \mathrm{~cm}$. This con trasts with the iridium anomaly at K-P sites (in the Pacific and elsewhere), which continues to be elevated outside the shockedquartz bearing intervals for up to a few $10 \mathrm{~s}$ of $\mathrm{cm}$, and is thought to be mobilized through diffusion [44]. Thus, in determining the nos $/ \mathrm{cm}^{2}$ at Pacific sites, we have assumed that the majority of the shocked quartz lies within the interval that is spherule-rich and from where shocked quartz has been previously identified. We recognize that there could be small numbers of K-P shocked quartz outside these intervals, and thus that the total abundance at Pacific sites is less well constrained than at other sites.

The maximum size, average size, average number of shocked quartz grains per $\mathrm{g}$, and total number of shocked quartz grains per $\mathrm{cm}^{2}$ all decrease with apparent distance (Fig. 5), and this is consistent with previous K-P studies $[14,26]$, as well as with observations of proximal ejecta around craters on other planetary bodies [41], and terrestrial volcanic craters [42]. The maximum size and abundance per $\mathrm{g}$ are best fit by power laws, abundance per $\mathrm{cm}^{2}$ by an exponential law, and mean size with a linear relationship (Fig. 5). In Figure 5 the solid dot is the apparent distance for 
ejecta with a take-off angle of 45 degrees, and the arrow indicates the change in apparent distance before the arrival of ejecta with a take-off angle of 70 degrees.

\section{Figure 5}

Even if our estimates of nos $/ \mathrm{cm}^{2}$ for the Pacific are slightly underestimated, they still appear to contradict previous reports that shocked quartz is relatively abundant in the Pacific [31, 32 ], that led to publications on the preferential westward distribution of the Chicxulub ejecta $[18,30,31]$. Schultz and D'Hondt [18] suggested that the North Pacific was downrange of the impact, whereas Alvarez et al. [30] argued that the ejection angle and Earth's rotation produced the high abundance of shocked quartz in the Pacific. The previously reported differences between the Pacific region and Europe occur, at least in part, because shocked quartz is more readily identified using SEM. However, our counts of the number of quartz grains per $g$ for the Pacific sites using SEM are different to those reported by Bostwick and Kyte [31]. They identified concentrations of 95 and 140 shocked quartz grain s per g in samples from ODP site 803D and 577B, whereas we identified between 5 and 10 grains per $g$ in sites at equivalent paleodistances and azimuths from Chicxulub. To verify our procedure we acquired a sample directly from one of the authors (Kyte), who provided us with $0.45 \mathrm{~g}$ of site GPC3 from the interval 2056-57 cm. Bostwick and Kyte [31] recovered 351 shocked quartz grains per g from this sample. We recovered 157 quartz grains from this sample, from which only 11 showed definitive evidence of shock metamorphism. This is equivalent to 24 grains per g and almost equal to our original result of 25 grains per $\mathrm{g}$ (Table 3 ). It appears that some aspect or aspects of sample preservation, sample handling, analytical techniques and mineral extraction procedures can lead to different absolute numbers of shocked quartz recovered and identified. We observe that Bostwick and Kyte's and our results are internally consistent: they both show a decrease in number of shocked grains towards the western Pacific. This forces the conclusion that individual results are protocol dependent, and that comparisons of results from unrelated studies are problematic. 


\subsection{Reproducibility and Dilution}

Our counts have been shown to be reproducible (within a factor of 2) with our aliquot tests on the Caravaca sample (Table 4a), and through our second count of a sample from site GPC3. Hence we are confident that our results are robust enough to be used for site-to-site comparisons. In the results section, we suggested that we could be underestimating our counts for samples diluted with large numbers of unshocked quartz by $\sim 40 \%$. We represent the possible effect of this dilution with a vertical bar in Figure 5c: the top of the bar represents the total counted quartz if we as sume an original underestimation by $40 \%$.

\subsection{Distribution of Shock level}

Petrographic descriptions from impact craters show that shock metamorphism is highly heterogeneous on a small scale, and small samples of target rock commonly contain mineral phases such as quartz and zircon that display a wide ran ge of shock metamorphic features. Thus, the range of shock features in ejecta at any one K-P site is likely to relate directly to the heterogen eous nature of the shocking process and also reflect mixing in the vapor plume prior to dispersal around the globe. However, the first ejecta incorporated within the expanding plume is, on average, the most highly shocked $[24,25]$, hence we might expect this to lead to a systematic change in degree of shock around the globe.

\section{Figure 6}

An indicator of the relative average degree of shock at each site has been estimated by determining the mean number of PDF in the shocked quartz grains (Table 4b). As an increasing numbers of PDF in quartz is ind icative of increasing shock pressures [39], the mean number of PDF is an approximate measure of the relative shock degree at each site. A plot of this estimated shock degree (mean number of PDF in shocked quartz) against apparent distance (Fig. 6a) shows that shock degree increases away from the impact site and is best described by a linear equation. A plot of the probability density functions (as determined from the means and variances in Table $4 \mathrm{~b}$ ) for 
grouped sites (Fig. 6b) shows that ODP site 1258A (shaded gray) plots to the right of all other sites. This indicates that the relative degree of shock is anomalously high at this site, and a two-tailed $\mathrm{T}$ test confirms this with a significance lev el of over $99 \%$.

Outputs from numerical models indicate that, in the early stages of impact, the target material is subjected to the highest shock compression pressures and is ejected from the crater at the highest velocities [25]. Although the initial ejection velocity is $\leq 2 \mathrm{kms}^{-1}$, this highly shocked material enters the first-forming outer part of the plume, and is then rapidly accelerated to high velocities during plume expansion [24]. Thus, the highest shocked material leaves the crater with the highest velocity and ends up furthest from the impact site. This is consistent with the observed gradual increase in shock degree with apparent distance (Fig. 6a). For oblique impacts the numerical model predicts that the shock varies with direction and that, for any particular distance from the impact site, the uprange ejecta is the most highly shocked [25]. The high mean shock degree for the sample from ODP site 1258A may, thus, be indicative of the uprange direction. Also, we note that site 1262, which is further away but in the same direction (Fig. 1b), has quartz grains that are slightly more highly shocked than expected. However, the error bars on this direction are currently quite large ( \pm 45 degrees). More observational data, as well as more numerical model runs for a range of different impact angles, are required before we can be more conclusive.

\subsection{Single or Multiple impacts?}

Several authors have suggested that there may have been more than one impact at the K-P boundary (e.g. [12]), and have referred to the 24-km Boltysh crater in the Ukraine which has been dated as $65.17 \pm 0.64 \mathrm{Ma}[47]$. A sub-vertical impact would produce symmetric ejection from the impact site, with a gradual decrease in number and size of shocked quartz grains with paleodistance that is independent of azimuth [25]. Accepting that we have only sampled a subset of regions around the globe, the observed size and shock-distribution of quartz at the global K-P layer are consistent with this layer having been formed from a single, sub-vertical, large impact at Chicxulub. 
It remains possible that impacts may have occurred around K-P times elsewhere, but unless they had been of similar magnitude to the Chicxulub event, they could not make a significant contribution to the shocked-quartz population at the global K-P boundary.

Stratigraphic interpretations of Cretaceous and Paleocene sections close to Chicxulub have recently been used to argue that the Chicxulub impact took place 300 ky prior to the K-P $[10,11]$. The gradual decrease in size and total number of particles (Fig. 5), and the gradual increase in shock (Fig. 6) with paleodistance from Chicxulub, indicate that the impact that produced the K-P distal ejecta layer occurred in the same region of the globe as Chicxulub. The presence of zircon of Yucatán basement age at the distal K-P layer in Canada [45], indicate that the K-P impact occurred into rock with the same basement age as Chicxulub, and the large volume of shocked quartz in the K-P layer tell us that the impact was into continental crust. These observations are all consistent with the more widely accepted interpretation that Chicxulub is of K-P age [e.g. 9, 38], and contrasting biostratigraphical interpretations of the micropaleontological data [48].

\subsection{Direction and angle of impact}

As discussed in the introduction, an oblique impact at Chicxulub could have produced an asymmetrical ejection of shocked quartz from the impact site. The relatively symmetrical size- and shock-distribution of shocked quartz around the globe, appears to suggest that the impact was not particularly oblique. However, the high shock levels in quartz at ODP site 1258A could be indicative of an uprange direction to the southeast \pm 45 degrees [25]. For oblique impact angles of $15^{\circ}$ to $45^{\circ}$ we would expect the proximal ejecta to be missing in the uprange direction [21], but thick sequences of proximal ejecta are observed to the southeast (Belize), east (Haiti) and south of Chicxulub (southern Mexico) [e.g 38]. These combined observations suggest that the impact, if oblique, was likely to be at an angle of $>45$ degrees.

\section{Conclusions}


A large volume of material was examined from the proposed K-P boundary at Poty Quarry in Brazil. We did not find shocked quartz within these samples, and conclude that this section is unlikely to be K-P in age. This is the first systematic study of shocked quartz at many K-P sites. The size and number of shocked quartz grains decrease with apparent distance from the Chicxulub crater, and this decrease is fairly symmetric. This contradicts previous studies that proposed that shocked quartz was more abundant than expected in the Pacific, and relatively rare in Europe. We conclude that individual analyses are protocol dependent, and that a comparison between unrelated studies may have led to the incorrect interpretation that the shocked quartz distribution was asymmetric. The observed relative degree of shock increases with apparent distance, and this is consistent with predictions from numerical models. Both the size-distribution and mean shock degree are precisely as expected, if the K-P layer was formed by a single, large, sub-vertical impact at Chicxulub. This contradicts recent publications that dispute the link between Chicxulub and the K-P boundary. The anomalous mean shock level at a site to the southeast of Chicxulub indicates that the impact may have been oblique, and that this site was uprange. However, the error bars on this direction are currently quite large. The presence of thick sequences of proximal ejecta at sites to the south, southeast and east of Chicxulub indicate that, if the impact was oblique and from the southeast, the impact angle was $>45^{\circ}$. Previous studies have predicted that Chicxulub produced a dramatic effect on the Earth's climate because it was formed by a low-angle oblique impact into volatile-rich sediments. Our results suggest that these more extreme predictions are unlikely.

\section{Acknowledgments}

This research was funded by a grant from the Leverhulme Trust. The authors would like to thank the Natural History Museum for their technical support, and in particular John Sprat, Terry Williams and Tony Willington. We also thank Finn Surlyk, University of Copenhagen, for support during sampling of the Danish site. Jan Smit and Frank Kyte are acknowledged for sharing their experience on the K-P boundary. Uwe Reimold and an anonymous reviewer are thanked for their 
reviews. This research used samples provided by the Ocean Drilling Program (ODP). ODP is sponsored by the U.S. National Science Foundation (NSF) and participating countries under management of Joint Oceanographic Institutions (JOI), Inc. IARC contribution no. 2005-1135.

\section{References}

[1] L. W. Alvarez, W. Alvarez, F. Asaro, H. V. Michel, Extraterrestrial cause for the Cretaceous-Tertiary extinction, Science 208 (1980) 1095-1108.

[2] J. Smit, F. T. Kyte, Siderophile-rich magnetic spheroids from the Cretaceous-Tertiary boundary in Umbria, Italy, Nature 310 (1983) 403-405.

[3] F. T. Kyte, J. A. Bostwick, Magnesioferrite spinel in Cretaceous-Tertiary boundary sediments of the Pacific basin: Hot, early condensates of the Chicxulub impact, Earth and Planetary Science Letters 132 (1995) 113-127.

[4] F. T. Kyte, J. Smit, Regional variations in spinel compositions: An important key to the Cretaceous/Tertiary event, Geology 14 (1986) 485-487.

[5] B. F. Bohor, E. E. Foord, P. J. Modreski, D. M. Triplehorn, Mineralogic evidence for an impact event at the Cretaceous-Tertiary boundary, Science 224 (1984) 867-869.

[6] B. F. Bohor, Shocked quartz and more: impact signatures in Cretaceous-Tertiary boundary clays, in: V. L. Sharpton, P. D. Ward (Eds.), Global Catastrophes in Earth History: an Interdisciplinary Conference on Impact, Volcanism and Mass Mortality, Geological Society America Special Paper, Boulder, Colorado, 1990, pp. 335-342.

[7] G. A. Izett, The Cretaceous/Tertiary boundary interval, Raton Basin, Colorado and New Mexico, and its content of shock-metamorphosed minerals; evidence relevant to the K-P boundary impact-extinction theory, Geological Society America Special Paper vol. 249, 1990, 100 pp.

[8] A. Montanari, Authigenesis of impact spheroids in the K/T boundary clay from Italy: New constraints for high-reso lution stratigraphy of terminal Cretaceous events, Journal of Sedimentary Petrology 61 (1991) 315339.

[9] A. R. Hildebrand, G. T. Penfield, D. A. Kring, M. Pilkington, A. Camargo, S. B. Jacobsen, W. V. Boynton, Chicxulub Crater: A possible Cretaceous/Tertiary boundary impact crater on the Yucatan Peninsula, Mexico, Geology 19 (1991) 867-871.

[10] G. Keller, T. Adatte, W. Stinnesbeck, M. Rebolledo-Vieyra, J Urrutia-Fucugauchi, Chicxulub impact predates the K-T boundary mass extinction, Proceedings National Academy Science 101 (2004) 3753-3758.

[11] G. Keller, T. Adatte, W. Stinnesbeck, D. Stuben, Z. Berner, U. Kramar, M. Harting, More evidence that the Chicxulub impact predates the K/T mass extinction, Meteoritics and Planetary Science 39 (2004) 11271144.

[12] G. Keller, W. Stinnesbeck, T. Adatte, D. Stuben, Multiple impacts across the Cretaceous-Tertiary boundary, Earth Science Reviews 62 (2003) 327-363.

[13] V. Courtillot, J. J. Jaeger, Z. Yang, G. Feraud, C. Hofman, The influence of continental flood basalts on mass extinctions: where do we stand? in: G. Ryder, D. Fastovsky, S Gartner (Eds.), The Cretaceous-Tertiary event and other Catastophes in Earth History, Geological Society of America Special Paper, Boulder, Colorado, 1996, pp. 513-525.

[14] K. Pope, Impact dust not the cause of the Cretaceous-Tertiary mass extinction, Geology 30 (2002) 99102.

[15] J. O'Keefe, T. Ahrens, Impact production of $\mathrm{CO}_{2}$ by the extinction bolide and the resultant heating of the Earth, Nature 338 (1989) 247-249.

[16] H. Sigurdsson, S. D'Hondt, J. Carey, The impact of the Cretaceous/Tertiary bolide on evaporite terrane and generation of major sulphuric acid aerosol, Earth and Planetary Science Letters 109 (1992) 543-559. 
[17] E. Pierazzo, J. Melosh, D. Kring, Hydrocode simulation of the Chicxulub impact event and climatically active gases, Journal of Geophysical Research 103 (1998) 28607-28625.

[18] P. H. Schultz, S. D'Hondt, Cretaceous-Tertiary impact angle and its consequences, Geology 24 (1996) 963-967.

[19] P. H. Schultz, Effect of impact angle on vaporization, Journal of Geophysical Research 101 (1996) 21117-21136.

[20] J. Morgan, M. Warner, J. Brittan, R. Buffler, A. Camargo, G. Christeson, P. Denton, A. Hildebrand, R. Hobbs, H. Macintyre, G. MacKenzie, P. Magu ire, L. Marin, Y. Nakamura, M. Pilkington, V. Sharpton, D. Snyder, G. Suarez, A. Trejo, Size and morphology of the Chicxulub impact crater, Nature 390 (1997) 472476.

[21] P. H. Schultz, Atmospheric effects on ejecta emplacement, Journal of Geophysical Research 97 (1992) $11623-11662$.

[22] A. R. Hildebrand, M. Pilkington, C. Ortiz-Aleman, R. E. Chavez, J. Urrutia-Fucugauchi, M. Connors, E. Graniel-Castro, A. Camara-Zi, J. A. Halpenny, D. Niehaus, Mapping Chicxulub structure with gravity and seismic reflection data, in: M. M. Grady, R. Hutchison, G. J. H. McCall, D. A. Rothery (Eds.), Meteorites: Flux with time and impact effects, Geological Society London, Special Publication vol. 14, 1998, pp. 177193.

[23] C. Eckholm, J. Melosh, Crater features diagnostic of oblique impacts: The size and position of the central peak, Geophysical Research Letters 28 (2001) 623-626.

[24] H. J. Melosh, Impact Cratering: A geologic process, New York, Oxford University Press, vol. 11, 1989, $245 \mathrm{p}$.

[25] J. Morgan, C. Lana, N. Artemieva, Shocked minerals in the K-T boundary: implications for the obliquity of impact (abstract), Lunar and Planetary Science 37 (2006)\#1281.

[26] M. Croskell, M. Warner, J. Morgan, Annealing of shocked quartz during atmospheric reentry, Geophysical Research Letters 29 (2002) 1940-1944.

[27] E. Argyle, The global fallout signature of the K-P bolide impact, Icarus 77 (1989) 220-222.

[28] D. Stöffler, N. A. Artemieva, E. Pierazzo, Modeling the Ries-Steinheim impact event and the formation of the moldavite strewn field, Meteoritics and Planetary Science 37 (2002) 1893-1907

[29] J. Melosh, Deep impact: The first second, Proceedings of Lunar and Planetary Science 37 (2006) 1165.

[30] W. Alvarez, P. Claeys, S. Kieffer, Emplacement of Cretaceous-Tertiary boundary shocked quartz from Chicxulub crater, Science 269 (1995) 930-935.

[31] J. A. Bostwick, F. T. Kyte, The size and abundance of shocked quartz in Cretaceous-Tertiary boundary sediments from the Pacific basin, in: G. Ryder, S. Gartner, D. Fastovsky (Eds.), The Cretaceous-Tertiary Event and Other Catastrophes in Earth History, Geological Society America Special Paper, Boulder, Colorado, 1996, pp. $403-415$.

[32] L. Zhou, F. T. Kyte, B. F. Bohor, The Cretaceous/Tertiary boundary of DSDP site 596, South Pacific, Geology 19 (1991) 694-697.

[33] A. Montanari, C. Koeberl, Impact stratigraphy: The Italian record, Heidelberg, Springer Verlag, vol. 93, $2000,364 \mathrm{p}$.

[34] G. A. Albertao, E. A. M. Koutsoukos, M. P. S. Regali, P. P. Martins, The Cretaceous-Tertiary Boundary in Southern low latitude regions: preliminary study in Pernambuco, northeastern Brazil, Terra Nova 6 (1994) 366-376.

[35] E. A. M. Koutsoukos, An extraterrestrial impact in the early Danian: A secondary K/T boundary event, Terra Nova 10 (1998) 68-73.

[36] W. Stinnesbeck, G. Keller, The Cretaceous-Tertiary boundary in southern low-latitude: preliminary study in Pernambuco, northeastern Brazil. Comments and Reply. Terra Nova 7 (1995) 375-382.

[37] W. Stinnesbeck, G. Keller, K-P boundary coarse-grained siliciclastic deposits in Northwestern Mexico and Northeastern Brazil, in: G. Ryder, S. Gartner, D. Fastovsky (Eds.), The Cretaceous-Tertiary Event and 
Other Catastrophes in Earth History, Geological Society America Special Paper Boulder, Colorado, 1996, pp. 197-210.

[38] J. Smit, The global stratigraphy of the Cretaceous-Tertiary boundary impact ejecta, Annual Review of Earth and Planetary Science 27 (1999) 75-91.

[39] D. Stöffler, F. Langenhorst, Shock metamorphism of quartz in nature and experiment: I. Basic observation and theory, Meteoritics 29 (1994) 155-181.

[40] B. F. Bohor, W. J. Betterton, T. E., Krogh, Impact-shocked zircons: Discovery of shock- induced textures reflecting increasing degrees of shock metamorphism, Earth and Planetary Science Letters 119 (1993) 419-424.

[41] A.M., Vickery, Variation in ejecta size with ejection velocity, Geophysical Research Letters 14 (1987) 726-729.

[42] http://volcano es.usgs.gov/ash/properties.html\#size

[43] H. Leroux, W. U., Reimold, C. Koeberl, U. Hornemann, J.-C. Doukhan, Experimental shock deformation in zircon: a transmission electron microscope study, Earth and Planetary Science Letters 169 (1999) 291-301.

[44] C. T. Lee, G. J. Wasserburg, F. T. Kyte, Platinum group elements (PGE) and rhenium in marine sediments across the Cretaceous-Tertiary boundary: Constraints on Re-PGE transport in the marie environment, Geochimica Cosmica Acta 67 (2003) 655-670.

[45] T. E. Krogh, S. L. Kamo, B. F. Bohor, U-Pb ages of single shocked zircons linking distal K-P ejecta to the Chicxulub crater, Nature 366 (1993) 731-734.

[46] S. L. Kamo, W. U. Reimold, T. E. Krogh, W. P. Colliston, A 2.023 Ga age for the Vredefort impact event and a first report of shock metamorphosed zircon in pseudotachylitic breccias and granophyre, Earth and Planetary Science Letters 144 (1996) 369-388.

[47] P. S Kelley, E. Gurov, Boltysh, another end-Cretaceous impact, Meteoritics and Planetary Science 37 (2002) 1031-1043.

[48] I. Arenillas, J. A. Arz, J. M. Grajales-Nishimura, G. Murillo-Muñeton, W. Alvarez, A. CamargoZanoguera, E. Molina, C. Rosales-Domínguez, Chicxulub impact event is Cretaceous/Paleogene boundary in age: New micropaleontological evidence, Earth and Planetary Science Letters 119 (2006), in press.

[49] P. Claeys, C. Kiessling, W. Alvarez, Distribution of Chicxulub ejecta at the Cretaceous-Tertiary boundary, in: C. Koeberl, K.G. MacLeod (Eds.), Catastrophic Events and Mass Extinctions: Impacts and Beyond, Geo logical Society America Special Paper, Boulder, Colorado, 2002, pp. 55-68. 


\section{Figure captions}

\section{Figure 1}

a) Photographs of lunar craters from Apollo 13. Arrows indicate the direction of travel of the impacting body. Highly oblique impacts produce elliptical craters and a butterfly ejecta pattern, impact angles up to $\sim 45$ degrees produce symmetrical craters with ejecta missing in the uprange direction [21]. Impacts of $>45$ degrees show continuous ejecta deposits around the crater.

b) K-P paleogeographic map showing maximum size of shocked quartz grains as collated by Claeys et al. [49]. Locations sampled for this study are id entified with a gray rectangle and numbered 1-15.

\section{Figure 2}

Grain size frequency histograms for shocked quartz grains recovered in K-P samples (see Table 1 and Fig. $1 \mathrm{~b}$ for location), and mean grain size at each site.

\section{Figure 3}

a), c), and d) are backscattered electron images; b) was taken in cross polarized light. a) Shocked quartz with two sets of planar deformation features (PDF) from ODP Site 1258A. b) Shocked quartz with partial isotropization (dark area in the center) from Berwind Canyon, North America. c) Partly recrystallized shocked quartz, showing two sets of PDF (arrows) and porous textures from Petriccio, Italy. d) Recrystallized shocked quart with internal porous textures from Caravaca, Spain. Porous textures are ind icative of recrystallization.

\section{Figure 4}

a-e) Backscattered electron images. a) Shocked zircon with multiple sets of planar deformation features (PDF) from Caravaca, Spain. Arrows point to the most continuous and straight sets. b) Recrystallized shocked zircon, showing porous texture. Partly recrystallized shocked zircon, with preserved euhedral shape and one set of planar fractures (arrow), from Petriccio, Italy. d-e) Polished sections showing internal structure of porous d) and fractured e) textures of shocked zircon from Caravaca, Spain. f) Cathodoluminescence image of shocked zircon grain shown in e), with multiple zoning and dark luminescent core.

\section{Figure 5}

Results from SEM analyses. Can. is Canada, 1258A is ODP Leg 207 site 1258A, GPC3 is Leg LL44 site GPC3, Den. is Denmark, 1209 is ODP Leg 198 sites 1209, 803D is ODP Leg 130 site 803D, 1262 is ODP Leg 208 site 1262, NZ is New Zealand. The horizontal axis is apparent distance, which incorporates paleo-reconstruction and rotation of the Earth during transit of the 
ejecta. The solid dots represent the distance from Chicxulub to the site for quartz ejected with a take-off angle of 45 degrees and traveling on a ballistic trajectory. The arrow indicates the change in distance prior to the arrival of quartz ejected at 70 degrees. The dashed line is the best-fit curve through all the data points; the corresponding equation and correlation coefficient (R) are given above the line.

a) The maximum and mean size of shocked quartz in $1 \mathrm{~g}$ samples of K-P boundary clay plotted against the apparent distance from Chicxulub.

b) The average number of shocked quartz found in $1 \mathrm{~g}$ samples of K-P boundary clay at each site, plotted against the apparent distance from Chicxulub. Vertical bars are the variance (Table 4b).

c) The total number of shocked quartz grains per unit surface area plotted against the apparent distance from Chicxulub. There is a systematic decrease in number of grains with increasing distance. The top of the vertical bar represents the count assuming a $40 \%$ underestimate of shocked quartz, for sites that might be affected by dilution with unshocked quartz (see text for more details).

\section{Figure 6}

a) The average number of PDF in shocked quartz grains from SEM analysis of $1 \mathrm{~g}$ samples of K-P boundary clay, plotted against the apparent distance from Chicxulub. See Figure. 5 for site abbreviations. Vertical bars are the variance (Table 4b). The dashed line is the best-fit linear equation through all data points except site 1258A; the corresponding equation and correlation coefficient are given on the graph. The mean number of PDF is a measure of the relative degree of shock at each site. The mean shock level increases with distance from Chicxulub. From the shocked quartz grains at ODP site 1258A an anomalously high mean shock level was determined.

b) Calculated probability density functions for the degree of shock at each impact site using the means and variances in Table 4b. N. Am includes all the sites from Canada and the USA; Europe includes all sites in Italy, Spain, and Denmark. Shocked quartz grains at ODP site 1258A plot to the right of all other sites, confirming their anomalously high mean shock level. 


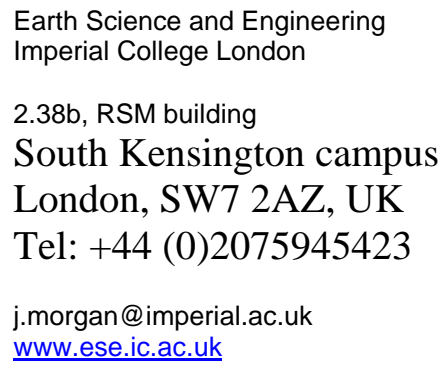

Dr Joanna Morgan PhD

\section{Dear Peggy}

We have revised the paper taking into account the suggestions by yourself and the two reviewers; details of our responses and actions are below.

Can you clarify whether K-P is the correct name for this boundary? I noticed that a new EPSL paper by Arenillas refers to this boundary as K-Pg.

regards

Jo Morgan \& Cristiano Lana

\section{Response to your comments}

We searched for sentences with the style "Something is shown in Figure/Table ..." and rephrased them as directed. [Apologies if we missed any]

We have removed ODP before occurrences of site GPC3.

We have shortened the text as requested. The length (abstract to acknowledgments) was 6400 words and is now $\sim 5700$.

With regards to providing a better explanation on how the nos $/ \mathrm{cm}^{2}$ is calculated. We have added the K-P layer thickness we used to Table 4b, and details on how the calculation was performed in the Table $4 \mathrm{~b}$ caption.

With regards to reviewer 1's assertion that we have incorrectly underestimated the shocked quartz at Pacific sites, we disagree and include a detailed response below. The reviewer is incorrect in their suggestion that the shocked quartz is focused in the same interval as the elevated iridium - this is not true at any K-P site. 


\title{
Response to Reviewer 2
}

\begin{abstract}
The suggested changes have all been made, except I preferred to change central to principal instead of chief, and I have not placed the "of" before \pm 45 . This would have incorrectly changed the meaning of that sentence.

\section{Introduction}

The first few sentences have been altered to acknowledge the lengthy debate prior to acceptance of the K-P impact and Chicxulub. This reviewer confuses the acceptance of a K-P meteorite impact and its acceptance as the cause of the extinctions. They are two quite separate issues. Everyone agrees that there was an impact, but many paleontologists believe the extinctions were gradual and suggest multiple causes. I have added a sentence to make this clearer. Everything else has been changed as directed.
\end{abstract}

\section{Sampling and Analytical Procedures}

We have changed the text as directed.

\section{Results}

The dilution paragraph was poorly written - hopefully it is clearer now.

We have removed the sentence on pervasive isotropization

Everything else has been changed as directed.

\section{Discussion}

We have tried to improve the description of the total abundance calculation (caption, Table 4b). We did not make the suggested heading change from "Distribution of shock" to "Distribution of shocked quartz" We are discussing the distribution of the degree of shock here. We have changed this heading to "Distribution of shock level".

We have not added references as requested because we have shortened the text here (to address the requirement to shorten the paper). In this section we have removed all the statements that this reviewer disagreed with.

We do not agree that it would have been sensible to include the unshocked quartz. There is no way of differentiating between quartz that is locally derived and unshocked quartz from Chicxulub. We have left the text as it is.

We have removed the discussion on the Boltysh crater related to it potentially being contemporaneous with Chicxulub.

Everything else in the discussion and conclusions has been altered as directed. 


\section{Response to Reviewer 1}

In the first figure below we show a typical plot of the K-P boundary and associated iridium concentration. Everyone agrees that the K-P fireball layer is a few mm thick at Carmel, Colorado, and that the shocked quartz is located almost entirely in this thin layer (there are small numbers within the boundary claystone). The background iridium is $<1 \mathrm{ppb}$. Anomalously high levels of iridium are found up to $10 \mathrm{~cm}$ below the fireball layer and extend to $\sim 20 \mathrm{~cm}$ above it.

The spread of the iridium anomaly at GPC3 and other sites in the Pacific are similar to that at Carmel - see second figure below. [Note that some people plot iridium on a log scale and others on a linear. A log scale tends to make slightly elevated iridium levels around the main peak more pronounced than when plotted on a linear scale]. The reason for the spread of the anomaly is almost certainly through diffusion, and possibly an extended residence time in the ocean in marine sections [Lee, Wasseburg and Kyte, PGE in marine sediments across the K-T boundary, Geochimica Cosmochemica Acta, vol 67, p 655-670, 2003). It is much easier to move the iridium than the much larger grains of shocked quartz (whatever the mechanism).

Where detailed sampling has been performed in the Pacific, for example site 576B (Table in Bostwick and Kyte [31]), the shocked quartz is focused within a relatively thin interval of $>3$ and $<7 \mathrm{~cm}$. (This table and the associated iridium plot are also shown below). From everything that I have read, this is typical of all K-P sites - the shocked quartz is focused in a relatively short interval and the iridium is more widely spread. In summary, there is no evidence for this reviewer's claims that the shocked quartz should occur in the same extended interval as the iridium in the Pacific, and thus that we have vastly underestimated the numbers in Pacific sites. We have added more details on the layer sampled in the first paragraph of section 2, and a discussion on the relative iridium/quartz spread in section 4.2. We have noted that there is some uncertainty on the dispersal of shocked quartz outside the sampled intervals in the Pacific sites.

With regards to the layers that this reviewer refers to as the ejecta layer (at the base) and the detrital clay layer (above), we have sampled both at all localities, including Woodside creek. We have added a few more sentences on sampling to the first paragraph in section 2 . In Italy the layer (the reviewer's two layers) varies from $2-4 \mathrm{~cm}$ thick, but is mostly closer to $2 \mathrm{~cm}$ thick. The K-T clay thickens locally due to low strain deformation (pers. com. Montanari). We chose to sample 2-cm sections as they were more typical, and the thicker sections might have been thickened during low strain deformation caused by either soft sediment deformation or uplift sedimentary strata. 
Iridium across K-T boundary at Carmel, Colorado

(from Izett, 1990)

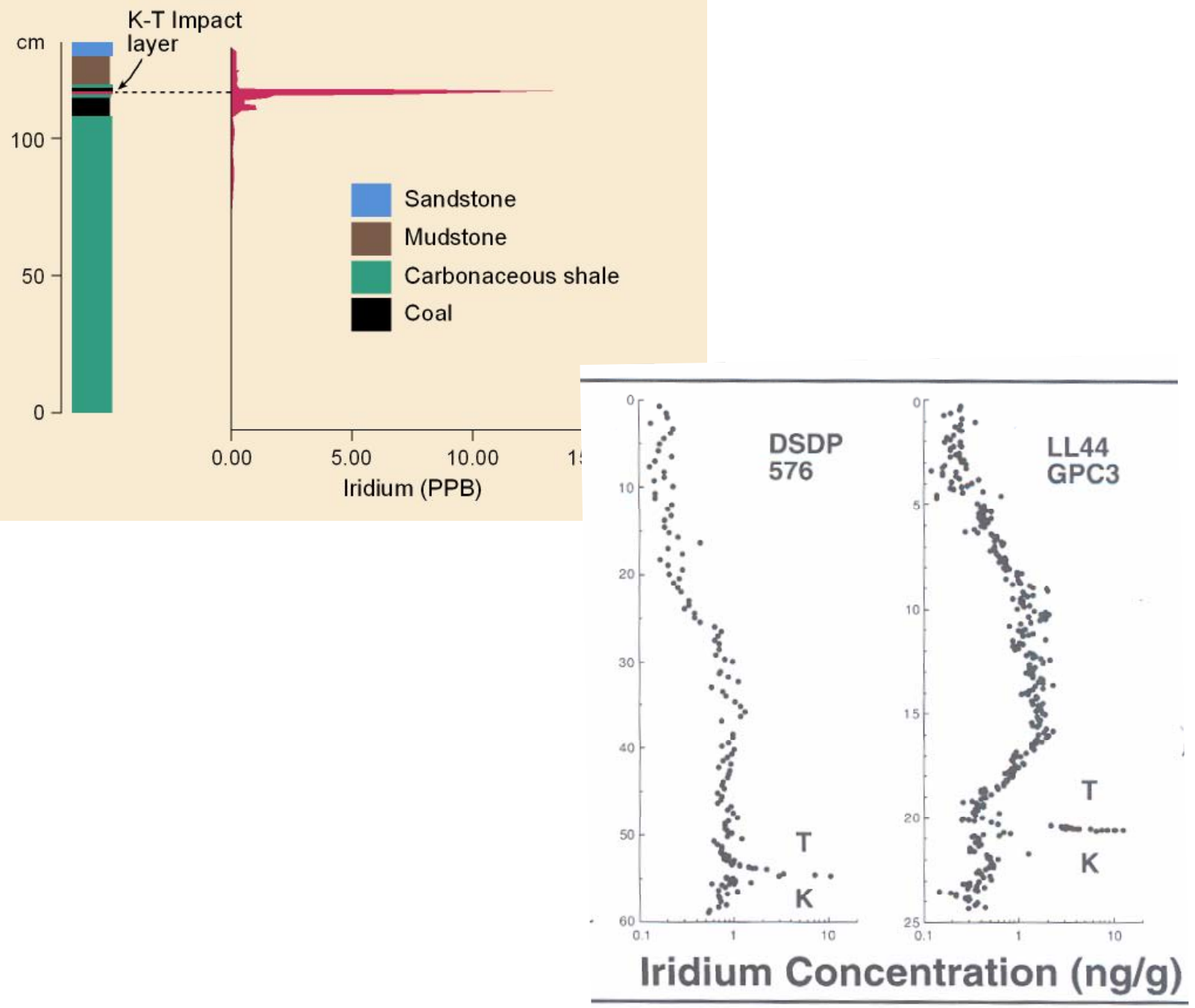

ons have been measured in sediments acrnse the $\mathrm{Co}_{0}$

TABLE 2. TRACE MINERAL CONTENT OF K/T BOUNDARY SEDIMENTS ON THE PACIFIC PLATE

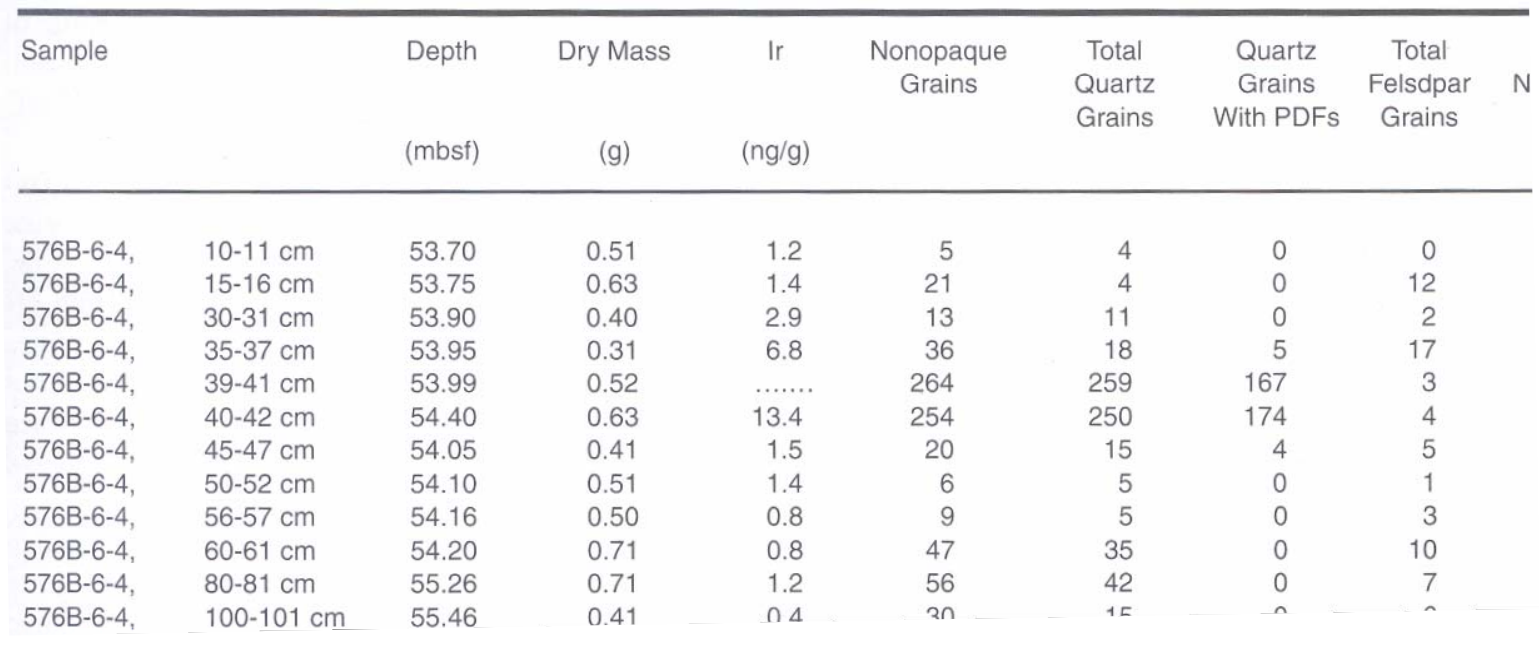




\section{Figure}

Click here to download high resolution image

\section{Figure 1}

a)
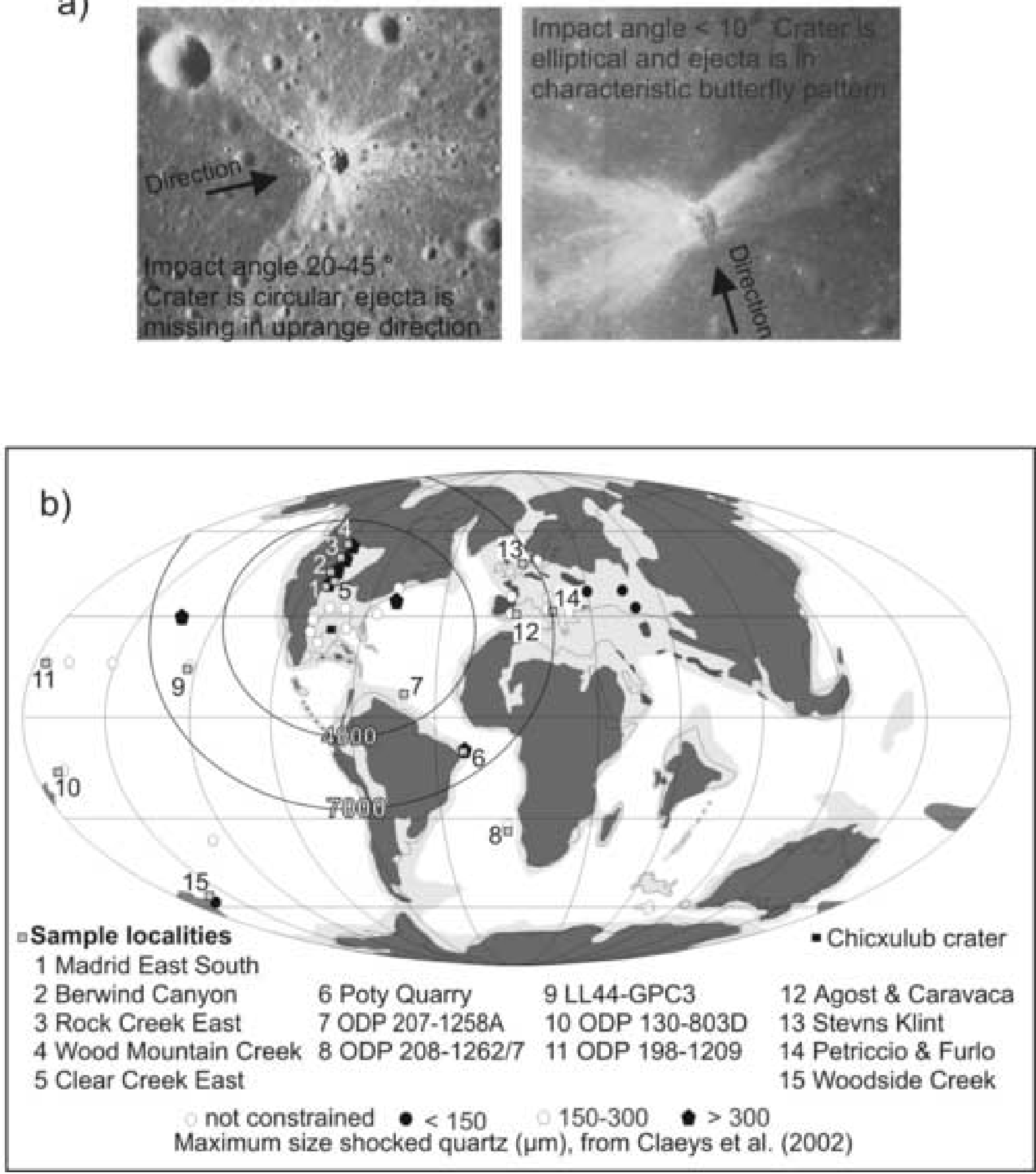

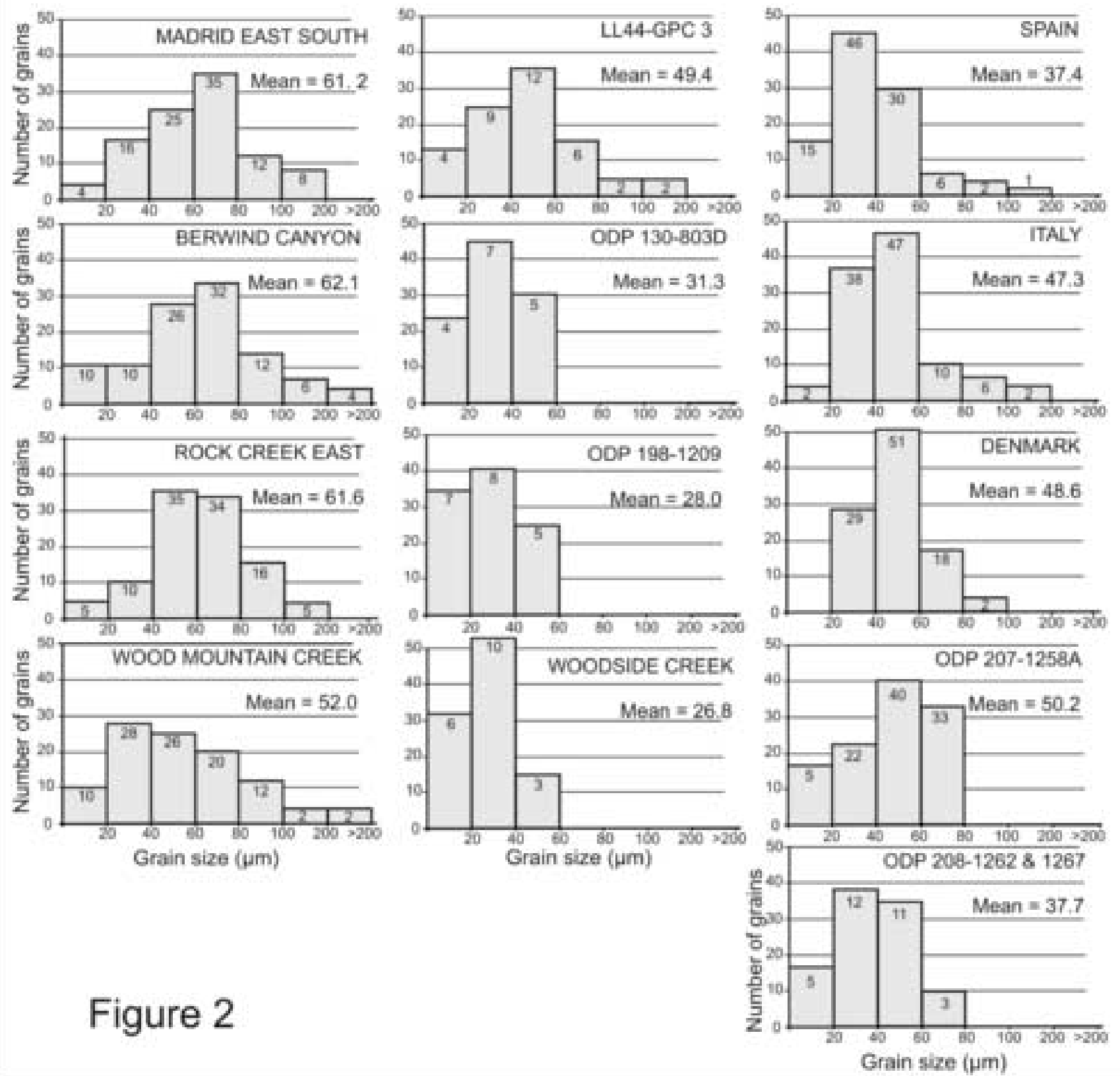

Figure 2 
Click here to download high resolution image

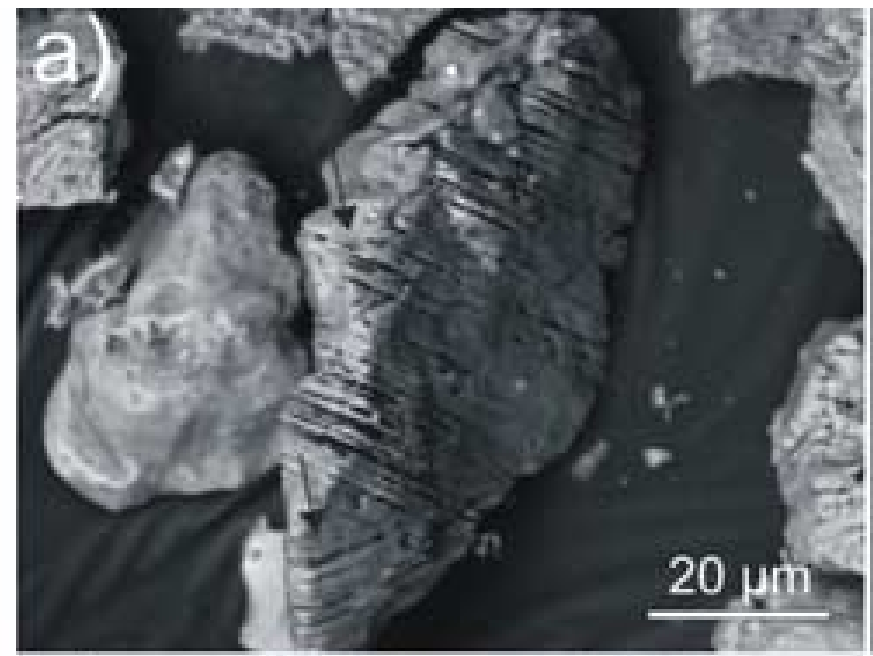

b)
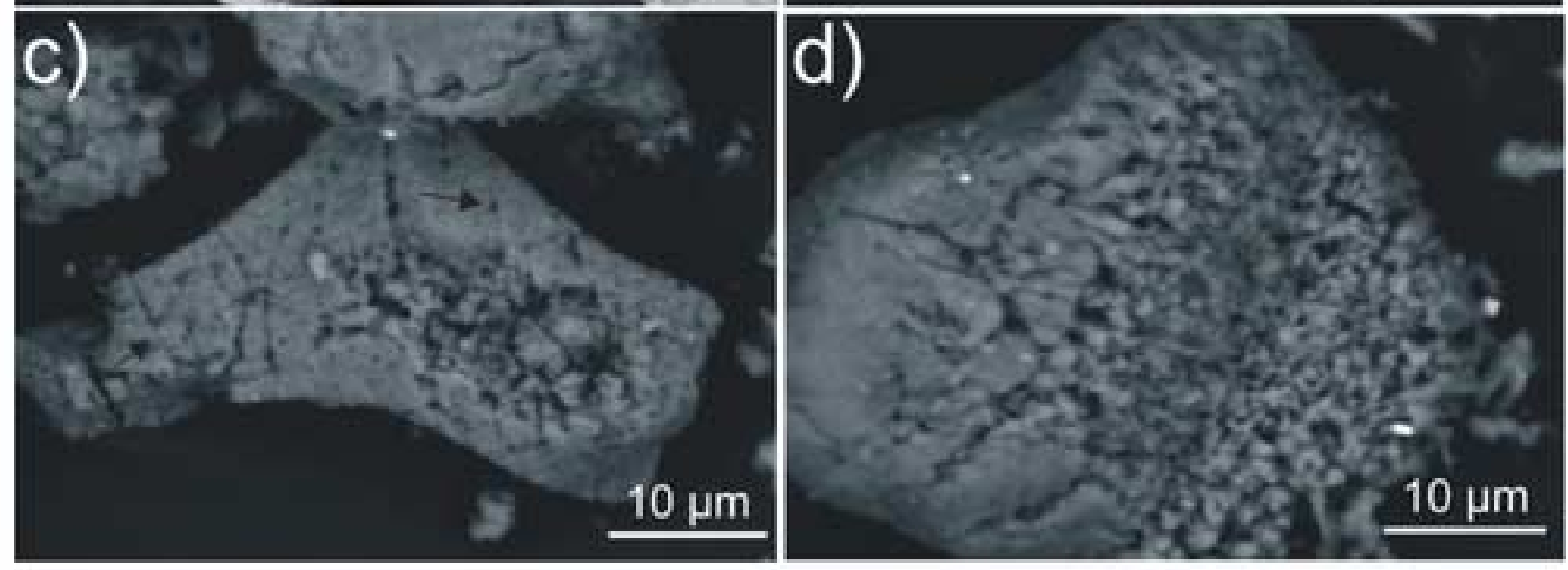

Figure 3 
Click here to download high resolution image
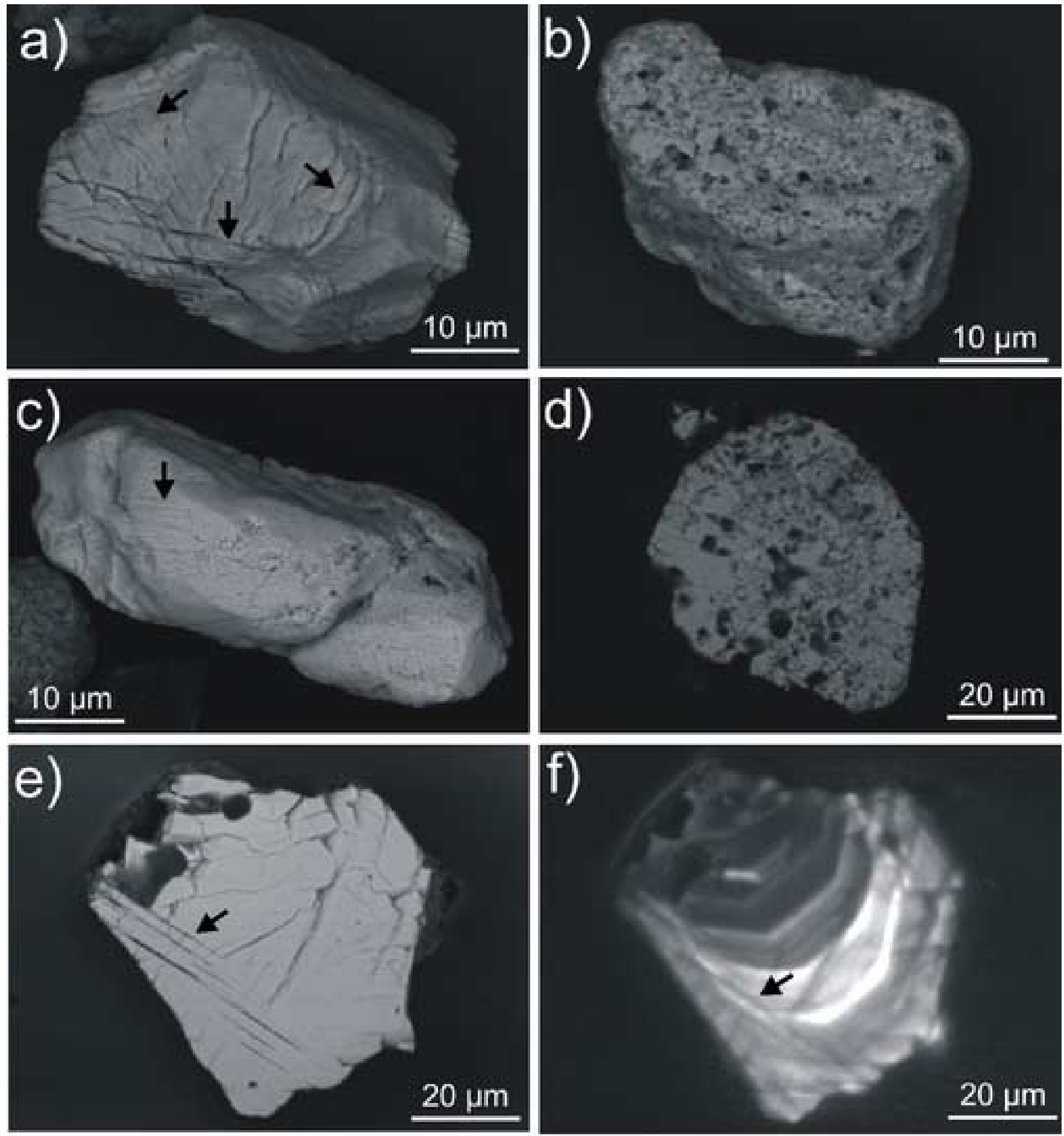

Figure 4 
Figure 5
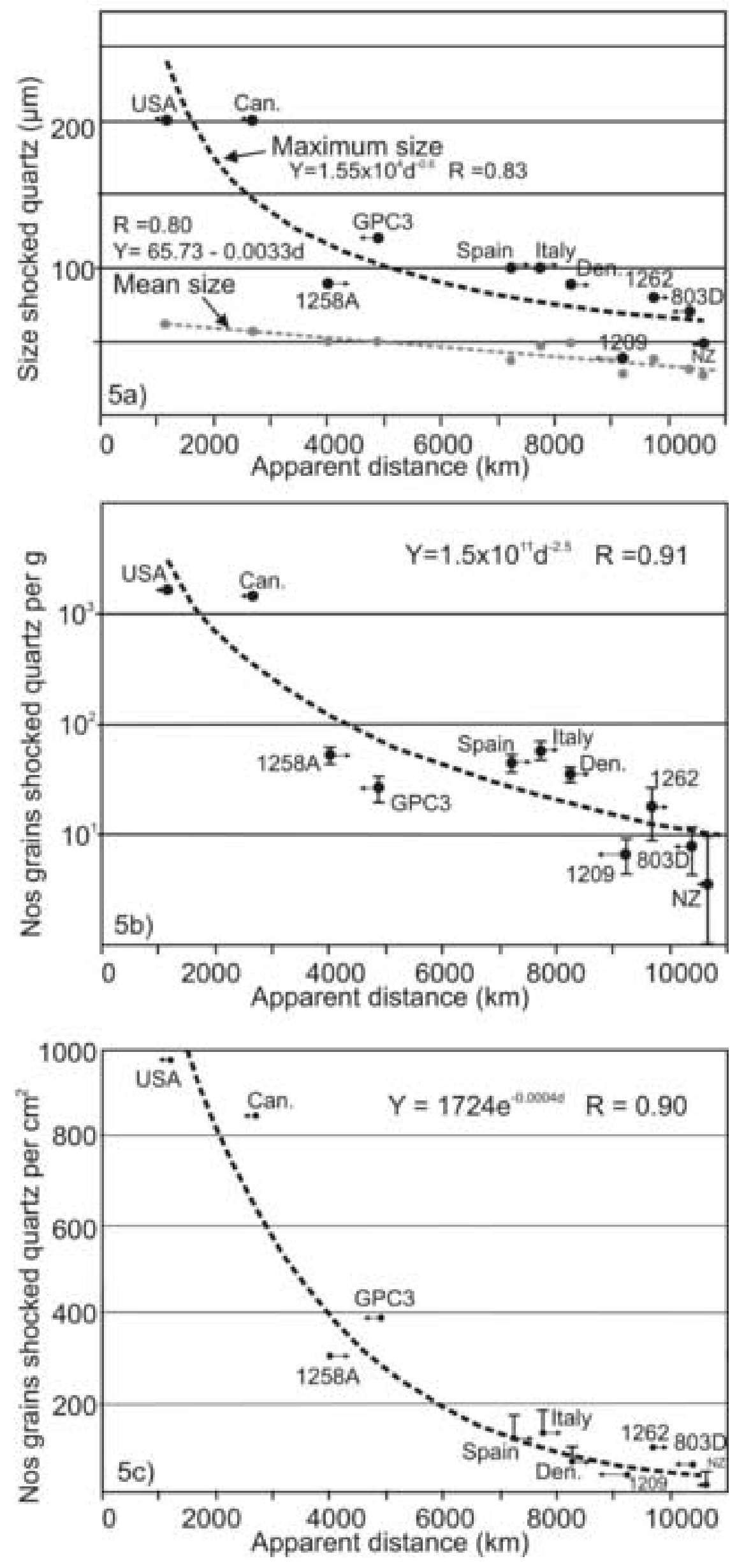


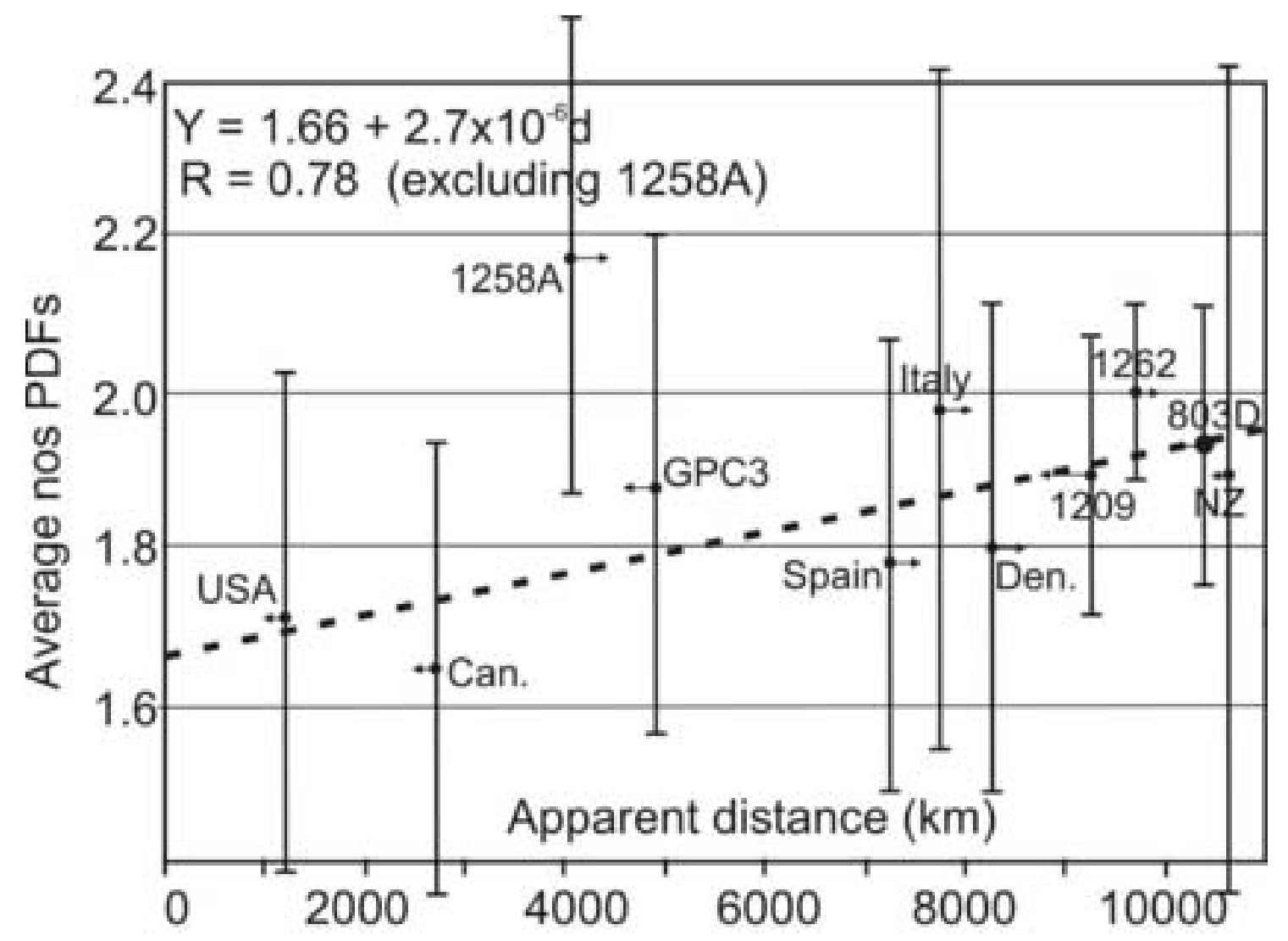

6a)

Figure 6

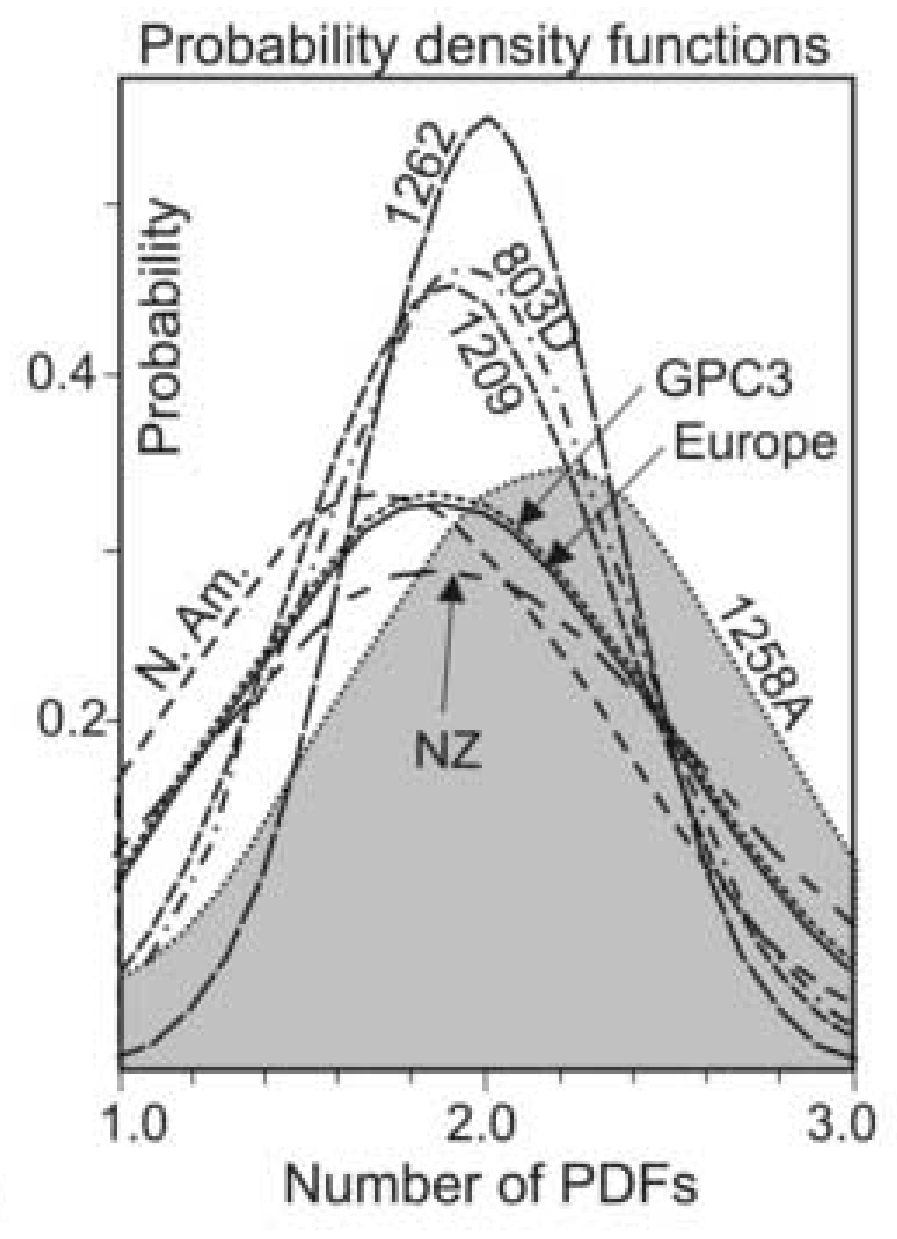

6b)

Number of PDFs 
Click here to download Table: newTable1.doc

\begin{tabular}{|c|c|c|c|c|c|c|}
\hline Location & K-T boundary sites & $\begin{array}{l}\text { Distance } \\
(\mathrm{km})\end{array}$ & $\begin{array}{l}\text { Paleo- } \\
\text { distance } \\
(\mathrm{km})\end{array}$ & $\begin{array}{l}\text { Azim } \\
\text { uth }\end{array}$ & $\begin{array}{l}\text { Depositional } \\
\text { environment }\end{array}$ & $\begin{array}{l}\text { Impact-related } \\
\text { minerals identified }\end{array}$ \\
\hline USA & $\begin{array}{l}\text { Clear Creek East } \\
\text { Berwind Canyon } \\
\text { Madrid East South }\end{array}$ & 2500 & $1000-1500$ & 315 & $\begin{array}{l}\text { Coal-swamp deposits } \\
<20 \text { m water depth [7] }\end{array}$ & $\begin{array}{l}\text { Shocked quartz } \\
\text { Shocked zircon }\end{array}$ \\
\hline Canada & $\begin{array}{l}\text { Rock Creek East } \\
\text { Wood Mountain Creek }\end{array}$ & 3800 & $2500-3000$ & 335 & $\begin{array}{l}\text { Coal-swamp deposits } \\
<20 \text { m water depth [7] }\end{array}$ & $\begin{array}{l}\text { Shocked quartz } \\
\text { Shocked zircon }\end{array}$ \\
\hline Brazil & Poty quarry & 7100 & $6000-6500$ & 120 & $\begin{array}{l}\text { Tsuna mi deposit }<500 \\
\text { m water depth }[34,35]\end{array}$ & \\
\hline Denmark & Stevns Klint & 10200 & $7500-8000$ & 65 & $\begin{array}{l}\text { Shallow marine }<100 \mathrm{~m} \\
\text { water depth [38] }\end{array}$ & $\begin{array}{l}\text { Shocked quartz } \\
\text { Ni-rich spinel }\end{array}$ \\
\hline Spain & Caravaca 1 & 8200 & $6500-7000$ & 75 & $\begin{array}{l}\text { Shallow marine }<500 \mathrm{~m} \\
\text { water depth [38] }\end{array}$ & $\begin{array}{l}\text { Shocked quartz } \\
\text { Shocked zircon } \\
\text { Ni-rich spinel }\end{array}$ \\
\hline Italy & Petriccio 1 & 9200 & $7000-7500$ & 80 & $\begin{array}{l}\text { Marine }<1000 \mathrm{~m} \text { water } \\
\text { depth [38] }\end{array}$ & $\begin{array}{l}\text { Shocked quartz } \\
\text { Shocked zircon } \\
\text { Ni-rich spinel }\end{array}$ \\
\hline $\begin{array}{l}\text { New } \\
\text { Zealand }\end{array}$ & Woodside Creek & 10500 & $\begin{array}{l}10500- \\
11000 \\
\end{array}$ & 195 & $\begin{array}{l}\text { Shallow marine } \\
<500 \mathrm{~m} \text { water depth }\end{array}$ & $\begin{array}{l}\text { Shocked quartz } \\
\text { Ni-rich spinel }\end{array}$ \\
\hline Pacific & LL44-GPC 3 & 7200 & $5000-5500$ & 250 & $\begin{array}{l}\text { Deep-water marine } \\
>3000 \mathrm{~m} \text { water depth } \\
\text { [31] }\end{array}$ & $\begin{array}{l}\text { Shocked quartz } \\
\text { Ni-rich spinel }\end{array}$ \\
\hline Pacific & ODP 198-1209 & 11400 & $\begin{array}{l}9500- \\
10000\end{array}$ & 260 & $\begin{array}{l}\text { Deep-water marine } \\
>2000 \mathrm{~m} \text { water depth } \\
\text { [31] }\end{array}$ & $\begin{array}{l}\text { Shocked quartz } \\
\text { Ni-rich spinel } \\
\text { Ni-rich pyroxene }\end{array}$ \\
\hline Pacific & ODP 130-803 D & 11600 & $\begin{array}{l}10500- \\
11000\end{array}$ & 220 & $\begin{array}{l}\text { Deep-water marine } \\
>2000 \mathrm{~m} \text { water depth } \\
\text { [31] }\end{array}$ & $\begin{array}{l}\text { Shocked quartz } \\
\text { Ni-rich spinel }\end{array}$ \\
\hline Atlantic & ODP 208-1262 & 9400 & $9000-9500$ & 125 & $\begin{array}{l}\text { Deep-water marine } \\
>2000 \text { m water depth }\end{array}$ & $\begin{array}{l}\text { Shocked quartz } \\
\text { Ni-rich spinel }\end{array}$ \\
\hline Atlantic & ODP 207-1258A & 4500 & $3500-4000$ & 110 & $\begin{array}{l}\text { Deep-water marine } \\
>2000 \mathrm{~m} \text { water depth }\end{array}$ & Shocked quartz \\
\hline
\end{tabular}

Table 1

Site locations, current distance from Chicxulub, distance from Chicxulub during the K-P, direction from Chicxulub during the K-P, depositional environment, and the impact related mineral identified in this study. See figure $1 \mathrm{~b}$ for site locations. ODP sites are identified by their leg and site number. 


\begin{tabular}{|c|c|c|c|c|c|c|c|}
\hline Location & Site & Sample & $\begin{array}{l}\text { Mass } \\
(\mathrm{g})\end{array}$ & $\begin{array}{l}\text { Nos quartz } \\
\text { (es timate) }\end{array}$ & $\begin{array}{l}\text { Nos } \\
\text { shocked } \\
\text { quartz } \\
\text { (counted) }\end{array}$ & $\begin{array}{l}\text { Max. size } \\
(\mu \mathrm{m})\end{array}$ & $\begin{array}{l}\text { Ave. Size } \\
(\mu \mathrm{m})\end{array}$ \\
\hline \multicolumn{8}{|c|}{ 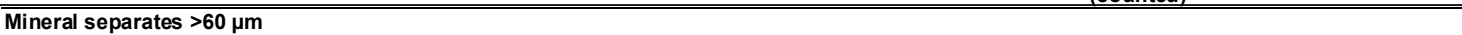 } \\
\hline \multirow[t]{7}{*}{ Italy } & Petriccio & PTC-1-30-11-2004 & 50 & $200-300$ & 11 & 120 & 95 \\
\hline & Petriccio & PTC-2-07-03-2005 & 50 & $200-300$ & 12 & 140 & 95 \\
\hline & Petriccio & PTC-3-07-03-2005 & 50 & $300-400$ & 9 & 160 & 110 \\
\hline & Petriccio & PTC-4-08-03-2005 & 50 & $300-400$ & 10 & 160 & 130 \\
\hline & Frontale & FRO-1-30-1-2004 & 50 & $200-300$ & 8 & 160 & 120 \\
\hline & Frontale & FRO-2-07-03-2005 & 50 & $200-300$ & 12 & 180 & 120 \\
\hline & Frontale & FRO-3-07-03-2005 & 50 & $100-200$ & 11 & 170 & 120 \\
\hline \multirow[t]{6}{*}{ Spain } & Agost & AG-2-10-03-2005 & 50 & $<1000$ & 4 & 140 & 120 \\
\hline & Agost & AG-3-10-03-2005 & 50 & $<1000$ & 6 & 160 & 110 \\
\hline & Caravaca & Cara-1-11-03-2005 & 50 & $<1000$ & 5 & 120 & 100 \\
\hline & Caravaca & Cara-2-11-03-2005 & 50 & $1000-1500$ & 5 & 100 & 77 \\
\hline & Caravaca & Cara-3-11-03-2005 & 50 & 1000 & 6 & 110 & 90 \\
\hline & Caravaca & Cara-4-11-03-2005 & 50 & $<1000$ & 7 & 120 & 80 \\
\hline \multirow[t]{8}{*}{ Denmark } & Stevns Klint & Quarry-1-09-03-2005 & 50 & $1000-2000$ & 8 & 180 & 150 \\
\hline & Stevns Klint & Quarry-2-09-03-2005 & 50 & $1000-2000$ & 7 & 160 & 110 \\
\hline & Stevns Klint & Quarry-3-09-03-2005 & 50 & $2000-3000$ & 5 & 160 & 120 \\
\hline & Stevns Klint & Quarry-4-09-03-2005 & 50 & $2000-3000$ & 7 & 140 & 110 \\
\hline & Stevns Klint & Quarry-5-09-03-2005 & 50 & $2000-3000$ & 7 & 150 & 115 \\
\hline & Stevns Klint & DNSIQ-1-09-03-2005 & 50 & $1000-2000$ & 4 & 140 & 90 \\
\hline & Stevns Klint & DNSIQ-2-09-03-2005 & 50 & $2000-3000$ & 8 & 160 & 90 \\
\hline & Stevns Klint & DNSIQ-3-09-03-2005 & 50 & $2000-3000$ & 9 & 140 & 90 \\
\hline \multirow{2}{*}{ New Zealand } & Woodside Creek & NZ-1-12-10-2004 & 50 & $>5000$ & 0 & 0 & 0 \\
\hline & Woodside Creek & NZ-2-22-10-2004 & 50 & $>5000$ & 0 & 0 & 0 \\
\hline \multirow[t]{11}{*}{ Brazil } & Poty Quarry & PT-1-Layer D-12-12-2004 & 50 & $>5000$ & 0 & 0 & 0 \\
\hline & Poty Quarry & PT-2-Layer D-21-01-2005 & 50 & $>5000$ & 0 & 0 & 0 \\
\hline & Poty Quarry & PT-3-Layer D-25-12-2004 & 50 & $>5000$ & 0 & 0 & 0 \\
\hline & Poty Quarry & PT-4-Layer D-29-12-2004 & 50 & $>5000$ & 0 & 0 & 0 \\
\hline & Poty Quarry & PT-5-Layer D-03-02-2005 & 50 & $>5000$ & 0 & 0 & 0 \\
\hline & Poty Quarry & PT-5-Layer D-25-12-2004 & 50 & $>5000$ & 0 & 0 & 0 \\
\hline & Poty Quarry & PT-5-Layer E-25-12-2004 & 50 & $>5000$ & 0 & 0 & 0 \\
\hline & Poty Quarry & PT-5-Layer F-21-01-2005 & 50 & $>5000$ & 0 & 0 & 0 \\
\hline & Poty Quarry & PT-5-Layer G-21-01-2005 & 50 & $>5000$ & 0 & 0 & 0 \\
\hline & Poty Quarry & PT-5-Layer H-03-02-2005 & 50 & $>5000$ & 0 & 0 & 0 \\
\hline & Poty Quarry & PT-5-Layer I-03-02-2005 & 50 & $>5000$ & 0 & 0 & 0 \\
\hline \multirow[t]{7}{*}{ USA } & Raton Basin & RAT-7-12-04-2004 / Fireball layer & 50 & $4000-6000$ & $5000\left(^{* *}\right)$ & 500 & 200 \\
\hline & Raton Basin & RAT-8-12-04-2004 / Boundary Claystone & 50 & $100-200$ & 14 & 80 & 80 \\
\hline & Berwind Canyon & BC-9-04-2005 / Fireball layer & 50 & $4000-6000$ & $4000\left(^{* *}\right)$ & 450 & 150 \\
\hline & Berwind Canyon & BC-12-04-2005 / Boundary Claystone & 50 & $100-200$ & 12 & 90 & 80 \\
\hline & Berwind Canyon & BC-11-04-2005 / Boundary Claystone & 50 & $100-200$ & 12 & 80 & 80 \\
\hline & Madrid East South & MES 7-12-04-2005 / Boundary Claystone & 50 & $100-200$ & 16 & 70 & 70 \\
\hline & Madrid East South & MES 6-12-04-2005 / Fireball Layer & 50 & $4000-6000$ & $5000\left(^{* *}\right)$ & 300 & 100 \\
\hline \multirow[t]{4}{*}{ Canada } & Rock Creek East & RCE8-12-04-2005 / Boundary Claystone & 50 & 400 & 20 & 80 & 60 \\
\hline & Rock Creek East & RCE6-12-04-2005 / Fireball Layer & 50 & $4000-6000$ & $4000\left(^{* *}\right)$ & 200 & 100 \\
\hline & Rock Creek East & RCE7-12-04-2005 / Boundray Claystone & 50 & 400 & 12 & 80 & 80 \\
\hline & Wood Mountain Creek & WMC-12-04-2005 / Fireball Layer & 50 & $4000-6000$ & $4000\left(^{* *}\right)$ & 200 & 80 \\
\hline \multicolumn{8}{|c|}{ Mineral separates $<100 \mu \mathrm{m}$} \\
\hline \multirow[t]{3}{*}{ Italy } & Petriccio & PTC-5-7-06-2005 & 50 & $300-400$ & 19 & 90 & 60 \\
\hline & Frontale & FOR - 07-06-2005 & 50 & $300-400$ & 18 & 90 & 60 \\
\hline & Frontale & FOR - 07-06-2005 & 50 & $500-600$ & 20 & 70 & 50 \\
\hline \multirow[t]{7}{*}{ Spain } & Agost & $A G-1-10-03-2005$ & 50 & $<1000$ & 12 & 100 & 90 \\
\hline & Agost & AG-4-10-03-2005 & 50 & $<2000$ & 11 & 100 & 90 \\
\hline & Agost & AG-5-10-03-2005 & 50 & $<2000$ & 16 & 80 & 50 \\
\hline & Caravaca & Cara-6-11-03-2005 & 50 & $1000-2000$ & 11 & 50 & 40 \\
\hline & Caravaca & Cara - 7 07-06-2005 & 50 & $1000-2000$ & 11 & 80 & 50 \\
\hline & Caravaca & Cara-1-11-03-2005 & 50 & $1000-2000$ & 20 & 90 & 50 \\
\hline & Caravaca & Cara-5-11-03-2005 & 50 & $<1000$ & 6 & 90 & 80 \\
\hline \multirow[t]{2}{*}{ Denmark } & Stevns Klint & DNSIQ-4-09-03-2005 & 50 & $2000-3000$ & 19 & 90 & 50 \\
\hline & Stevns Klint & DNSIQ-5-10-03-2005 & 50 & $2000-3000$ & 20 & 90 & 50 \\
\hline \multirow[t]{4}{*}{ New Zealand } & Woodside Creek & NZ-1-10-03-2004 & 50 & $>3000$ & 2 & 50 & 45 \\
\hline & Woodside Creek & NZ-2-10-03-2004 & 50 & $>3000$ & 3 & 40 & 35 \\
\hline & Woodside Creek & NZ-3-10-03-2004 & 50 & $>3000$ & 2 & 50 & 45 \\
\hline & Woodside Creek & NZ-4-10-03-2004 & 50 & $>3000$ & 4 & 100 & 75 \\
\hline
\end{tabular}

Table 2

Optical analyses on mineral separates from land-based sites. Samples are named by their location and date of analysis. The total number of quartz grains has been estimated, whereas the number of shocked quartz grains have been carefully counted. The mean size is calculated using all identified shocked quartz grains, except for North American samples for which 100 grains were used to calculate the mean. 


\begin{tabular}{|c|c|c|c|c|c|c|c|c|c|c|}
\hline Location & Site & $\begin{array}{l}\text { Mass } \\
(\mathrm{g})\end{array}$ & $\begin{array}{l}\text { Location } \\
(\mathrm{cm})\end{array}$ & $\begin{array}{l}\text { Nos of } \\
\text { quartz } \\
\text { (estimated) }\end{array}$ & $\begin{array}{l}\text { Nos shock. } \\
\text { quartz } \\
\text { (counted) }\end{array}$ & $\begin{array}{l}\text { Max. } \\
\text { size } \\
(\mu \mathrm{m})\end{array}$ & $\begin{array}{l}\text { Ave. } \\
\text { size } \\
(\mu \mathrm{m})\end{array}$ & $\begin{array}{l}1 \text { Set } \\
\text { of PDF } \\
(\%)\end{array}$ & $\begin{array}{l}2 \text { Sets } \\
\text { of PDF } \\
(\%)\end{array}$ & $\begin{array}{l}3 \text { Sets } \\
(\%)\end{array}$ \\
\hline Pacific & ODP 198-1209 & 1 & $85-86$ & $20-50$ & 8 & 20 & 20 & 25 & 75 & 0 \\
\hline Pacific & ODP 198-1209 & 1 & $84-85$ & $20-50$ & 5 & 40 & 20 & 20 & 60 & 20 \\
\hline Pacific & ODP 198-1209 & 1 & $83-84$ & $20-50$ & 7 & 30 & 20 & 0 & 100 & 0 \\
\hline Pacific & LL44-GPC 3 & 1 & $2051-52$ & $40-70$ & 0 & 0 & 0 & & & \\
\hline Pacific & LL44-GPC 3 & 1 & $2052-53$ & $40-70$ & 22 & 90 & 50 & 22.7 & 54.6 & 22.7 \\
\hline Pacific & LL44-GPC 3 & 1 & $2053-54$ & $40-70$ & 14 & 120 & 6 & 14.2 & 85.8 & 0 \\
\hline Pacific & LL44-GPC 3 & 1 & $2054-55$ & $50-100$ & 33 & 70 & 50 & 24.2 & 57.6 & 18.2 \\
\hline Pacific & LL44-GPC 3 & 1 & $2056-57$ & $50-100$ & 25 & 80 & 60 & 24 & 68 & 8 \\
\hline Pacific & LL44-GPC 3 & 1 & $2058-59$ & $50-100$ & 45 & 80 & 50 & 29 & 60 & 11 \\
\hline Pacific & LL44-GPC 3 & 1 & $2059-60$ & $40-70$ & 0 & 0 & 0 & & & \\
\hline Pacific & ODP $130-803$ D & 1 & $60-62$ & 100 & 6 & 70 & 40 & 16.6 & 66.8 & 16.6 \\
\hline Pacific & ODP $130-803$ D & 1 & $62-64$ & 100 & 10 & 50 & 40 & 10 & 90 & 0 \\
\hline Atlantic & ODP 208-1262 & 1 & $78.5-81.5$ & $100-200$ & 11 & 80 & 50 & 9 & 82 & 9 \\
\hline Atlantic & ODP 208-1262 & 1 & $78.5-81.5$ & $100-200$ & 23 & 80 & 50 & 4.3 & 91.4 & 4.3 \\
\hline Atlantic & ODP 207-1258A & 1 & $91.0-94.0$ & $50-100$ & 44 & 90 & 40 & 9 & 82 & 9 \\
\hline Atlantic & ODP 207-1258A & 1 & $91.0-94.0$ & $50-100$ & 42 & 70 & 40 & 9.5 & 50 & 40.5 \\
\hline Atlantic & ODP 207-1258A & 1 & $91.0-94.0$ & $50-100$ & 68 & 90 & 50 & 10.2 & 60.4 & 69.4 \\
\hline Spain & Caravac a 1 & 1 & botto $\mathrm{m} \mathrm{cm}$ & $500-1000$ & 35 & 70 & 40 & 23 & 69 & 7.7 \\
\hline Spain & Caravac a 2 & 1 & botto $\mathrm{m} \mathrm{cm}$ & $500-1000$ & 52 & 110 & 45 & 40 & 51.4 & 8.6 \\
\hline Spain & Caravac a 3 & 1 & top $\mathrm{cm}$ & $500-1000$ & 16 & 110 & 45 & & & \\
\hline Italy & Petriccio 1 & 1 & botto $\mathrm{m} \mathrm{cm}$ & $50-100$ & 74 & 80 & 40 & 32.4 & 50 & 17.6 \\
\hline Italy & Petriccio 2 & 1 & botto $\mathrm{m} \mathrm{cm}$ & $500-1000$ & 52 & 80 & 50 & 11.5 & 67.3 & 21.2 \\
\hline Italy & Petriccio 3 & 1 & top cm & $500-1000$ & 12 & 100 & 50 & & & \\
\hline Italy & Frontale 1 & 1 & botto $\mathrm{m} \mathrm{cm}$ & $500-1000$ & 39 & 110 & 50 & 20.5 & 51 & 28.2 \\
\hline Denmark & Stevns Klint 1 & 1 & botto $\mathrm{m} \mathrm{cm}$ & $2000-3000$ & 29 & 90 & 60 & 17.3 & 82.7 & 0 \\
\hline Denmark & Stevns Klint 2 & 1 & botto $\mathrm{m} \mathrm{cm}$ & $2000-3000$ & 33 & 80 & 60 & 27.7 & 39.6 & 3 \\
\hline Denmark & Stevns Klint 3 & 1 & top $\mathrm{cm}$ & $2000-3000$ & 0 & 0 & 0 & & & \\
\hline Denmark & Stevns Klint 4 & 1 & top $\mathrm{cm}$ & $2000-3000$ & 6 & 90 & 60 & & & \\
\hline New Zealand & Woodside Creek 1 & 2 & botto $\mathrm{m} \mathrm{cm}$ & $2000-3000$ & 11 & 50 & 40 & 54 & 36 & 0 \\
\hline New Zealand & Woodside Creek 2 & 2 & botto $\mathrm{m} \mathrm{cm}$ & $2000-3000$ & 8 & 30 & 25 & 25 & 75 & 0 \\
\hline New Zealand & Woodside Creek 3 & 2 & botto $\mathrm{m} \mathrm{cm}$ & $2000-3000$ & 5 & 40 & 30 & 20 & 60 & 20 \\
\hline New Zealand & Woodside Creek 4 & 2 & bottom $\mathrm{cm}$ & $2000-3000$ & 16 & 40 & 30 & 18.8 & 37.5 & 43.7 \\
\hline New Mexico** & Clear Creek East & 0.5 & $0.3 \mathrm{~cm}$ & $>1000$ & 800 & 200 & $80 *$ & $31^{*}$ & $55^{*}$ & $14^{*}$ \\
\hline Colorado** & Berwind Canion & 0.5 & $0.3 \mathrm{~cm}$ & $>1000$ & 794 & 200 & $75^{*}$ & $38^{*}$ & $48^{*}$ & $14^{*}$ \\
\hline Colorado** & Madrid East South & 0.5 & $0.3 \mathrm{~cm}$ & $>1000$ & 840 & 120 & $60 *$ & $34^{*}$ & $62^{*}$ & $4^{*}$ \\
\hline Canada** & Rock Creek East & 0.5 & $0.3 \mathrm{~cm}$ & $>1000$ & 640 & 150 & $80 *$ & $32^{*}$ & $64^{*}$ & $4^{*}$ \\
\hline Canada** & Rock Creek East & 0.5 & $0.3 \mathrm{~cm}$ & $>1000$ & 720 & 200 & $70^{*}$ & $44^{*}$ & $51^{*}$ & $5^{*}$ \\
\hline Canada** & Wood Mountain Creek & 0.5 & $0.3 \mathrm{~cm}$ & $>1000$ & 760 & 200 & $65^{*}$ & $44^{*}$ & $50^{*}$ & $6^{*}$ \\
\hline
\end{tabular}

(*) average of 100 grains

(**) Fireball Layer only

Table 3

Results from SEM analyses. The location column indicates sampling depth at ODP sites, bottom or top centimeter at European sites, the entire 1-cm thick K-P layer in New Zealand, and layer thickness at North American sites. The number of quartz grains is estimated, whereas the nu mber of shocked quartz are carefully counted. The average size is for all shocked quartz in the sample, except for North American sites for which the average is based upon 100 measured grains. Similarly, the number of PDF in each quartz grain is for all shocked quartz grains in a sample, except for North American sites for which the values are determined from 100 quartz grains. 


\begin{tabular}{lll}
\hline Sample & $\begin{array}{l}\text { Weight } \\
\text { (g) }\end{array}$ & $\begin{array}{l}\text { Number of } \\
\text { shocked quartz }\end{array}$ \\
\hline Optical analys is & & \\
Cara-1-2-03-2006a & 50 & 4 \\
Cara-1-2-03-2006b & 50 & 7 \\
Cara-1-2-03-2006c & 50 & 8 \\
Cara-1-2-03-2006d & 50 & 3 \\
Average & & 5.5 \\
Standard deviation & \multicolumn{2}{l}{2.3} \\
Scanning electron microscopy analysis \\
Cara-1-2-03-2006a & 1 & 37 \\
Cara-1-2-03-2006b & 1 & 24 \\
Cara-1-2-03-2006c & 1 & 38 \\
Cara-1-2-03-2006d & 1 & 19 \\
Average & & 29.5 \\
Standard deviation & & 9.5 \\
\hline
\end{tabular}

Table $4 \mathrm{a}$

Results from four aliquots of the same sample from Caravaca Spain.

\begin{tabular}{lccccccccc}
\hline Location & $\begin{array}{c}\text { Apparent } \\
\text { Distance }\end{array}$ & $\begin{array}{c}\text { Apparent } \\
\text { Azimuth }\end{array}$ & \multicolumn{2}{c}{$\begin{array}{c}\text { Nos } / g \\
\text { Mean }\end{array}$} & $\begin{array}{c}\text { Mean } \\
\text { Variance } \\
(\mu \mathrm{m})\end{array}$ & $\begin{array}{c}\text { Int. } \\
(\mathrm{cm})\end{array}$ & $\begin{array}{c}\text { Nos/cm } \\
\text { (2) }\end{array}$ & \multicolumn{2}{c}{$\begin{array}{c}\text { Nos PDF } \\
\text { Mean }\end{array}$} \\
\hline USA & 1150 & 323 & 1623 & 25 & 62 & 0.3 & 973 & 1.71 & 0.37 \\
Canada & 2650 & 341 & 1413 & 61 & 57 & 0.3 & 848 & 1.65 & 0.33 \\
ODP 207-1258A & 4000 & 108 & 51 & 15 & 50 & 3 & 307 & 2.17 & 0.34 \\
LL44-GPC3 & 4850 & 250 & 28 & 12 & 50 & 7 & 390 & 1.88 & 0.36 \\
Spain & 7200 & 76 & 44 & 12 & 37 & 2 & 119 & 1.78 & 0.33 \\
Italy & 7700 & 81 & 55 & 18 & 47 & 2 & 134 & 1.98 & 0.44 \\
Denmark & 8250 & 67 & 34 & 5 & 49 & 2 & 68 & 1.8 & 0.26 \\
ODP 198-1209 & 9200 & 260 & 7 & 2 & 28 & 3 & 40 & 1.9 & 0.19 \\
ODP 208-1262 & 9700 & 123 & 17 & 9 & 38 & 3 & 102 & 2 & 0.12 \\
ODP 130-803D & 10350 & 218 & 8 & 3 & 31 & 4 & 64 & 1.94 & 0.18 \\
New Zealand & 10600 & 191 & 5 & 5 & 27 & 1 & 10 & 1.9 & 0.49 \\
\hline
\end{tabular}

Table $4 \mathrm{~b}$

Summary of results from the SEM analyses. The apparent distance and azimuth incorporate paleoreconstruction, and rotation of the Earth during transit of material ejected at 45 degrees and traveling on a ballistic path. Nos/g is the mean number of shocked quartz grains per $\mathrm{g}$, and is determined by averaging all samples at the specified location. Nos $/ \mathrm{cm}^{2}$ is the number of shocked quartz grains per unit area of the Earth's surface, and is determined using the mean number of shocked quartz grains in each sampled layer (Table 3), summing each layer across the entire K-P interval from which shocked quartz has been extracted (Int. in table above), and using a density of 2 $\mathrm{gcm}^{2}$. For example, in Italy the layer thickness is $2 \mathrm{~cm}$, and the mean number of grains per $\mathrm{g}$ are 55 and 12 in the bottom and top cm respectively. Hence, in a volume that is $1 \mathrm{~cm}^{2}$ by $2 \mathrm{~cm}$ deep (mass $4 \mathrm{~g}$ ), the nos $/ \mathrm{cm}^{2}$ is $67 \times 2=134$. SEM analyses were not performed on the boundary claystone from USA and Canada, hence Int. at these sites is for the fireball layer only. If the boundary claystone were included we estimate that the nos $/ \mathrm{cm}^{2}$ would increase by $50-100$ grains at each of these two locations. The mean number of PDF is determined from the last three columns in Table 3. 